\title{
1 Autonomous induction of hepatic polarity to construct single cell liver.
}

2 Yue Zhang ${ }^{1}$, Richard de Mets ${ }^{1}$, Cornelia Monzel ${ }^{2}$, Pearlyn Toh ${ }^{1}$, Noemi Van Hul ${ }^{3,4}$,

3 Soon Seng $\mathrm{Ng}^{5}$, S.Tamir Rashid ${ }^{5,6}$, Virgile Viasnoff ${ }^{1,7,8}$

4

5

6

7

$8{ }^{2}$ Institut Curie, 5 rue Curie 75005 Paris. France

$9{ }^{3}$ Department of Biosciences and Nutrition, Karolinska Institutet, Stockholm, Sweden

$10{ }^{4}$ Institute of Molecular and Cell Biology (IMCB), A*STAR, Singapore.

11

${ }^{5}$ Centre for Stem Cells and Regenerative Medicine, King's College London, London, United Kingdom.

${ }^{6}$ Institute for Liver Studies, King's College Hospital, King's College London, London, United Kingdom.

${ }^{7}$ Department of Biological Science, National University of Singapore.

${ }^{8}$ Centre National de la Recherche scientifique UMI 3639, 117411 Singapore 


\section{Abstract}

21 Symmetry breaking of protein distribution and cytoskeleton organization is an essential aspect for development of apico-basal polarity. In embryonic cells this process is largely cell autonomous, while differentiated epithelial cells collectively polarize during epithelium formation. We report here that the de novo polarization of mature hepatocytes is a cell autonomous process. Single hepatocytes developed bona fide secretory hemi-apical lumens upon adhesion to finely tuned substrates bio-functionalized with cadherin and extra cellular matrix. The creation of this single cell liver allows unprecedented control and imaging resolution of the lumenogenesis process. We demonstrate that the density and localization of cadherins along the initial cell-cell contact acted as a key factor triggering the reorganization from lateral to apical actin cortex. Consequently, we established why hepatocytes could form asymmetric lumens in heterotypic doublets involving another ectopic epithelial cell originating from kidney, breast, or colon.

\section{Introduction}

36 The development of apico-basal polarity in epithelial cells requires signaling from the extracellular matrix as well as from cell-cell contact. The matrix/cell junction direction provides an axis of external cues along which epithelial cells break their symmetry (1-3), organize their acto-myosin cortex (4), and direct the vectorial transport of proteins $(5,6)$. Mechanical constrains and tension also play a role (7-9). The segregation of membrane proteins between apical, basal, and lateral poles are also ensured by the fencing activity of tight junctions as well as by the antagonist pathways of the polarity complexes (Par1/Par2, Par3/Par6/aPKC, Crumbs and Scribble complexes). The situation differs in the early embryo when single cells can polarize in the absence of external cues. In single cell C.elegans embryo, Par 1 and Par 3 complexes segregate based on antagonist kinase activity $(10,11)$ and actomyosin cortical flow (12). In mouse embryo, blastocysts develop apical poles $(13,14)$ in the absence of extracellular matrix interactions in a fully cell autonomous manner $(15,16)$. Over activation of LKB1 in single epithelial cells was also reported to stimulate the creation of a border brush with a partial localization of the polarity 
complexes (17).The question then arises whether de novo establishment of epithelial polarity is a cell autonomous response triggered by external cues or a collective response associated to the concomitant development of polarity in neighboring cells. Usual epithelial models (tissue, cell monolayer, or cysts) inherently fail to address this question. Considering a cell polarizing in these multi-cellular contexts, the concomitant reorganization of cell-cell contacts of the neighboring cells can act as a polarization cue and as a response to its polarization establishment.

This study presents a novel model where single primary hepatocytes develop independent bona fide secretory apical poles when grown in synthetic microenvironments. In this context, we demonstrate for the first time that de novo apical lumen development is a genetically controlled cell autonomous process. It depends mainly on actin cortex rearrangements triggered by the biophysical properties of the cadherin-mediated adherens junction along the initial lateral cellcell contact. Subsequently, we demonstrate that, hepatocytes can form functional lumen with a whole variety of epithelial cells. In particular, we show that mature hepatocytes can polarize with immature hepatocytes during the differentiation process.

\section{Results:}

We investigated the de novo lumenogenesis of bile canaliculi to test if the apical polarity development is a cell autonomous process triggered by simple cues sensed by the cell along the non-polarized initial cell-cell contact. We used hepatocytes at different maturation stages during differentiation. Mature hepatocytes develop intercellular secretory apical lumen called bile canaliculi, connecting the hepatocytes to the biliary system. They consist of small, elongated tubules ( $2 \mu \mathrm{m}$ in diameter) sealed by tight junctions and extending between two adjacent cells (Figure 1a). Bile salt transporters (eg:BSEP) and ion pumps (eg:MRP2) accumulate at the apical membrane to secrete bile into the lumen. We differentiated hiPSCs (human induced pluripotent stem cells) over 25 days $(18,19)$ into hepatocytes lineage during which the hepatoblast-to-hepatocyte differentiation took 6 days in vitro (20). During this hepatic lineage induction, we observed a mixed population of cells at different maturation stages (21). To assess hepatocyte maturity, we used the expression levels 
and localization of a small organic anion transporter MRP2 (Multidrug resistanceassociated protein 2). A mixed population of mature and immature hepatocytes was plated in micro-fabricated cavities bio-functionalized with fibronectin (see protocol). We previously established that such cavities forced cell-cell contacts to enable lumen formation (9). We found that homotypic junction between two mature, MRP2 positive hepatocytes expectedly developed a canaliculus (Figure 1a). The lumen displayed a symmetric accumulation of MRP2 exclusively at their apical membrane. The apical pole from both cells displayed characteristic actin enrichment. The lumens were inflated due to the proper localization of tight junctions at their edges (Figure 1a). We also observed a sizeable fraction $(40 \% \pm 5)$ of heterotypic junctions between mature and immature hepatocytes ( $\mathrm{MRP2}^{+} / \mathrm{MRP2}^{-}$cells). They displayed strikingly asymmetric apical lumens (Figure 1a). The luminal membrane of the mature hepatocyte (MRP2 ${ }^{+}$) was identical to the canaliculus formed in homotypic junctions between mature hepatocytes. By contrast, the membrane of the immature hepatocyte (MRP2) lacked actin enrichment and was hardly curved. However, tight junctions, as shown by the presence of ZO1, properly sealed the edges of the asymmetric lumens (Figure 1a and Supplementary Figure 1a). The asymmetric apical arrangement of canaliculi suggested that the nature of the cell adjacent to a mature hepatocyte might not be critical for the hepatocyte to establish apical basal polarity. To further test this hypothesis, we induced heterotypic contacts between primary rat hepatocytes $(22,23)$ and epithelial cell lines derived from various species and organs: EPH4, a murine breast cell line, Madin Darby Canine Kidney cells (MDCK), a dog kidney cell line and Caco2, a human colorectal adenocarcinoma cell line. Monolayer co-cultures of these cell lines lead to spontaneous segregation of the population. However, constraining the cells in microcavities $(25 \times 25 \times 25 \mu \mathrm{m})$ favored the establishment of stable heterotypic contacts. A large number of lumens formed along these heterotypic contacts. They presented the proper localization of the respective apical markers for each cell type (MRP2 for the hepatocytes, GBP35 for MDCK, Figure 1b and Supplementary Figure 1b). All luminal membranes exhibited microvilli. ZO1 also localized at the lumen edge indicating a normal polarized state for both cells. The large inflation of the lumen revealed an efficient paracellular barrier and the development of transluminal osmotic gradients. 
115 This result demonstrated that the development of interspecific lumens occurs in the

116 absence of inhibitory mechanisms. It supports the hypothesis that apico-basal 117 polarity develops stably upon response to signaling cues ubiquitous to epithelial cell 118 types. In the heterotypic doublets, the organization of the tight junctions was nonetheless symmetrical. We thus could not decipher if the polarity is triggered autonomously based on cues present at the initial cell-cell contact, or if it requires

121 the concomitant organization of both cells in a coordinated manner.

122 We then tested if single hepatocytes could autonomously polarize in absence of 123 polarizing neighboring cells. To this end, we first cultured and fixed 124 (paraformaldehyde 4\%) MDCK monolayers at 65\% confluence and used them as an 125 "inert" substrate to culture fresh primary rat hepatocytes (Material and Methods). A substantial fraction of single hepatocytes ( $\sim 50 \%$ ) developed unusual accumulation of

127 actin filaments or actin rings at the interface between the MDCK monolayer and the 128 hepatocytes (Figure 1c). ZO1 accumulated around these actin rings. We reasoned that these structures could constitute the basis of a polarized domain that selforganized upon the engagement of hepatocytes in an E-cadherin mediated contact with the fixed MDCK.

133 To test this hypothesis we reconstituted cell-cell and cell-matrix interactions in vitro 134 using biofunctionalized substrates enabling precise control of the interaction and high-resolution imaging. We screened various environmental conditions

136 (Supplementary Figure 2a). On $700 \mu \mathrm{m}^{2}$ circular islands coated with fibronectin, 137 single hepatocytes spread and organized their actin cytoskeleton around the pattern showing no sign of polarity, and this irrespective of whether the culture medium was 139 supplemented with $6 \%$ Matrigel. On identical islands coated with E or $\mathrm{N}$ cadherins, 140 single cells developed central actin rings at the interface with the substrate only for 141 Matrigel supplemented medium (Supplementary Figure 2b).Note that Hepatocytes express equally $\mathrm{E}$ and $\mathrm{N}$-Cadherins (24). MRP2 was recruited within the membrane area delineated by the actin ring. Similar results were obtained for primary mouse 144 hepatocytes (Supplementary Figure 2c).

145 We further tested if the inner ring membrane was a functional secretory apical pole 146 as suggested by the localization of the anion transporter MRP2. Confocal imaging did 
not reveal any convincing detachment of the membrane from the substrate suggesting either a hemi-luminal cavity below optical axial resolution (around $700 \mathrm{~nm}$ ) or a collapse during fixation. We thus used Reflection Interference Contrast Microscopy (RICM) to measure the nanoscale distance between the substrate and 151 the plasma membrane in label-free living cells (25). This revealed (Figure 2 a) that 152 the membrane enclosed by the actin rings had a concave shape on average. The 153 membrane pulsated up and down at mean period of $6 \mathrm{~min} /$ pulse. $(\mathrm{N}=9)$. The hemi154 lumen reached maximal heights of $170 \pm 5 \mathrm{~nm}(\mathrm{~N}=25)$. Upon partial inhibition of bile 155 salt synthesis by $10 \mu \mathrm{m}$ Ketoconazole, the lumen period increased by to fold to 12 $\mathrm{min} /$ pulse. It also enhanced lateral fluctuations of the intraluminal membrane as compared to the concentric axial pulsation observed in control case (Figure $2 \mathbf{a}$ and 158 Supplementary movies 1-2). Additionally, actin filaments no longer formed a 159 characteristic ring but remained structured as a patch in the center of the contact. 160 We also added UDCA (Ursodeoxycholic acid, $40 \mu \mathrm{M}$ ) to the cell culture media to stimulate bile secretion, which resulted in three-fold increase $(633 \pm 54 \mathrm{~nm} \mathrm{~N}=16)$ in lumen maximal height. The central lumen was largely inflated as demonstrated by the multiple circular interference fringes along the lumen. Our data strongly suggested that the hemi-lumens formed between hepatocyte and cadherin-coated micropattern were functional and recapitulated the pulsatile behavior of canaliculi observed in vivo. The small level of inflation of the lumen (around 200nm as compared to 2 to $5 \mu \mathrm{m}$ in vivo) could be explained by the expected large paracellular leak resulting from a contact with the substrate that is established exclusively by cadherins and likely lacking tight junctions. We then tested the extent to which the spatial self-organization of junctional and polarity markers resulting solely from E-

171 cadherin adhesion mimicked the organization of true canaliculi. Figure $\mathbf{2} \mathbf{b}$ shows the 172 positions of cellular cadherin, ZO1/ZO2, Par-3, Claudin-3, Myosin IIA, MRP2 relative 173 to the actin ring. The stereotypical shape of the ring enabled the computation of the 174 average localization map (Figure $2 \mathrm{c}$ and Supplementary Figure 3 ) for each protein 175 (Material and Methods). From this map we found that myosin II microfilaments 176 accumulated strongly along the ring. Structured illumination microscopy 177 (Supplementary Figure 7) revealed their radial orientation across the orthoradial 178 actin fibers constituting the ring, strongly suggesting that the ring is highly 
contractile. ZO1/ZO2 and Par3 accumulated precisely at the edge of the actin ring (Figure 2b,c). Cellular cadherin (Material and Methods) was absent from the central region of the ring, accumulated $1.5 \pm 0.5 \mu \mathrm{m}$ away from the outer edge of the ZO1ZO2-Par3 ring and was diffusively present along the rest of the contact with the substrate. We concluded that proper lateral, junctional, and basal domains developed at the contact with the substrate as pictured on Figure $\mathbf{2 d}$. Note however that the different concentric rings extend laterally over $2 \pm 0.5 \mu \mathrm{m}$. In canaliculi formed between 2 cells, the peri-canalicular acto-myosin ring was smaller than 2 microns, and ZOs and Par3 localized around a 200-300 nm away from the actin belts (26). Additionally, the main trans-membrane tight junction proteins claudin3 and 1 and occludin did not show specific accumulation on any membrane region, indicating a lack of structuration of the transmembrane components of the tight junction components (Supplementary Figure 3a). The minimalistic cues provided by our system not only polarized the cortical and membrane components at the contact but also structured the position of the Golgi. 3D reconstitution following Grasp65 staining (Supplementary Figure $\mathbf{3 b}$ ) revealed that the Golgi was located precisely (95\% overlap $\mathrm{N}=40$, Material and Methods) over the actin ring region. It extended vertically to reach the nucleus independently of the position of the nucleus in the cells. Although it was previously reported that cadherin and integrins are necessary to elicit the development of apical poles $(2,3)$, in our model the polarity developed without cell division (as in classical type of approaches (27)) and by a single cell in contact with an inert substrate. Taken together, we established that combining static cadherin and extracellular matrix adhesions is sufficient to induce a fully polarized protein distribution which phenocopied the apico-basal polarization of hepatocytes (except for occludin and claudins) (Figure 2d). Our data demonstrated that polarity program in mature hepatocytes is fully autonomous and does not require the response of the neighboring cells past the initial induction by E-cadherin contact.

We then established the time sequence of events leading to the development of apico-basal polarity after it was triggered by mere E-cadherin contact. We classified the development of the hemi-lumen into five phases based on 
the different prevailing acto-myosin structures imaged by structured illumination

211 microscopy, SIM (Figure 3).

212 Phase 1: 3 h pre matrigel induction. Cells first adhered to the E-cad patterns. During 213 this phase an acto-myosin ring accumulated at the cell edge. Cadherins and ZO1 co214 localized with the ring. Other markers showed no specific localization.

215 Phase 2: Oh to $4 \mathrm{~h}$ post induction. Disorganized actin fibrils developed at the center of 216 the cell contact with the substrate. Myosin IIA and ZO-1 were recruited along these 217 fibers. Par3 accumulated diffusively in the central region.

218 Phase 3: 4h to 7 post induction. A diffuse acto-myosin patch developed in the 219 center of the cells ( $50 \%$ cases, $N=56)$. ZO1/2 accumulated at the outer edge of the 220 patch into a discontinuous ring. Par3 and MRP2 localized diffusively over the patch. 221 Cadherin attachment to the substrate remained homogenous across the whole 222 contact area.

223 Phase 4: 7h to $14 \mathrm{~h}$ post induction. The acto-myosin patch densified into a 224 disorganized central region surrounded by radial fibers. Myosin was largely recruited 225 on the disorganized patch (Supplementary Figure 7). Cadherin detached from the 226 underlying substrate beneath the central patch region. Polarity markers (ZO1-2, 227 Par3) were densely recruited around the interface between the patch and the radial 228 fibers. MRP2 accumulated within the central patch region.

229 Phase 5: $14 \mathrm{~h}$ post induction. Hepatocytes developed the ring phenotype described 230 previously (Figure 2 ) with $85 \%$ occurrence rate $(\mathrm{N}=72)$. Note that $\mathrm{ZO} / \mathrm{2}$ were fully 231 excluded from the edge of the cell. The transition from Phase 4 to Phase 5 was 232 suppressed by inhibition of myosin II or bile secretion (Supplementary Figure 4), 233 strongly suggesting that the transition from actin patch to actin ring was 234 mechanically driven by acto-myosin contractility and osmotic gradients.

235 We then tested if this time sequence of events is compatible with the development 236 of real lumens between two cells. We performed 3D SIM imaging of different 237 development stages on the canaliculi (Supplementary Figure 5). They displayed 238 gradual accumulation of a denser actin cortex (300 nm thick) at the center of the 239 contact and the gradual relocalization of ZO1 and Par 3 from the contact edge to the 240 lumen edge. Lumen inflation occurred in multiple locations along the actin dense 241 patch. We attributed this effect to the maturation of tight junctions concomitant to 
242 the disengagement of adherens junctions. This leads to the local development of 243 micro lumens that eventually merged into one lumen. We concluded that the 244 process of canaliculi development in vivo and in our reductionist single cell liver 245 follow a very similar sequence of events. The time sequence of events we observed 246 also share similarities with what has been described as pre-apical actin patches (PAP) 247 and Apical Membrane Initiation Sites (AMIS) $(4,28)$ in MDCK doublets. However, in 248 our case the actin structure formed in vivo is far more localized at the membrane 249 than what is reported for MDCK PAP (4).

251 We then determined how the density and spatial arrangement of cadherin regulates 252 lumen formation. We first modulated the total amount of cadherin adhesion by 253 changing the shape and size of the pattern while keeping cadherin density constant. 254 Independent of the pattern's shape and size (Supplementary Figure 6), lumens 255 formed with identical rate of occurrence, and remained circular with an area of 200 $256 \mu \mathrm{m}^{2} \pm 60$. Unconstrained hepatocytes left to spread on un-patterned homogeneously 257 coated cadherin substrates also polarized. These lumens were more irregular in 258 shape, and could reach an area of $600 \mu \mathrm{m}^{2}$ for very large contacts $\left(2400 \mu \mathrm{m}^{2}\right)$. We 259 concluded that in our reductionist approach the lumen size and shape were largely 260 decoupled from the size and shape of the cadherin contact area.

261 Next, we varied cadherin density on the $30 \mu \mathrm{m}$ circular pattern (Material and 262 methods). Figure 4a shows that at low cadherin densities the hepatocytes did not 263 attach. As the cadherin density increase the number of hepatocytes adhering to the 264 substrate continuously increased, however the occurrence of lumen formation 265 peaked significantly at a coating density of $10 \mu \mathrm{g} / \mathrm{ml}$ cadherin. Lower and higher 266 cadherin densities proved less efficient in prompting lumen formation suggesting 267 that there is an optimal density of cadherin for triggering apical surface 268 development. We used western blotting to assess the quantity of cadherins. In 269 ascending expression levels, the cell lines ranked as MDCK < EPh4 < Caco2 270 (Supplementary Figure $1 \mathbf{b}$ ). In the heterodoublets the probability of asymmetric 271 lumens formation was inversely correlated with the amount of cadherin. MDCK cells 272 had the lowest expression levels of cadherin and proved the most efficient in 273 creating heterolumens. We then overexpressed E-cadherin in Eph4 cells (Eph4 ${ }^{+}$) to 
reach the expression level found in Caco2 cells. It resulted in a lower occurrence of

275 lumen formation matching that matching Caco2 heterodoublets (Figure 4a). We thus

276 concluded that apical pole formation requires a fine balance of cadherin adhesion.

277 On one hand it should allow cell-cell contact and on the other hand should not over-

278 stabilize it. This parameter appears to be key for the ability of hepatocytes to

279 develop mature lumens with their adjacent neighbors. We then tested if the spatial 280 distribution of cadherin also affected lumen formation. We seeded our single 281 hepatocytes on circular cadherin patterns $(30 \mu \mathrm{m} Q)$ containing an antifouling 282 coating in their central region $(15 \mu \mathrm{m} \mathrm{Q})$. On the center of these doughnut patterns, 283 we matched the size of the non-adhesive region to the average size of lumens 284 formed on disc patterns (Figure 4b). All these hepatocytes failed to form a secretory 285 hemi-lumen, and the membranes remained suspended over the non-adhesive part 286 of the lumen as demonstrated by the random and stochastic fluctuations probed by 287 RICM live imaging (Supplementary Video 4). On average, this resulted in a flat top288 hat profile of the membrane height as compared to the dome shape profile observed when lumens formed (Figure $\mathbf{4 b}$ ). The actin structure remained cortical with no radial fibers (Figure 4c), and never developed into a ring. ZO-1 and Par-3 291 relocated to the central zone but did not organize along the contour of actin patch 292 (Figure 4c). These data suggested that the local adhesion of cadherins at the center 293 of the contact was essential for polarity establishment. Correlatively, signaling from 294 cadherins outside the future luminal area was not sufficient to trigger the formation 295 of apical poles. We concluded that the lumen development originated from the local 296 engagement of cadherins rather than from an integrated signal over the whole 297 contact.

298 We reasoned that the development of actin fibers (P2 phase) and the subsequent 299 diffuse actin patch (P3 phase) from an actin poor contact area (P1 phase) was an essential process in the subsequent self-organization of the apical pole. To test this 301 hypothesis we impaired the development of the fibers while still maintaining the full 302 capacity of the hepatocytes to self-organize. We plated the hepatocytes on a 303 substrate homogeneously coated with E-cad that was studded with small 304 topographical features (comprising of pillars or a grid with dimensions ranging from 3052 um to $500 \mathrm{~nm}$ in width, and 800nm in height, Material and Methods). Hepatocytes 
were able to attach to such substrates, spreading on and in-between the 307 topographical features. Despite the homogeneous E-cadherin coating, all the feature 308 types tested resulted in inhibition of the development of P2 like actin fibers (Figure 4d). Actin accumulated around each topographical feature fully coated with Ecadherin.

311 Upon addition of matrigel, most of the actin failed to restructure and remained largely "clamped" by the topography. This resulted in a drastic reduction of

313 hepatocytes with a polarized phenotype (75\% polarization in the absence of 314 features, compared to $20 \%$ polarization on micropillars, $25 \%$ on nanopillars, and $15 \%$ on nanogrids, Figure 4 d). The few polarized cells (discriminated by an actin structure surrounded by ZO1 and Par3) exhibited a much smaller apical area (2 20\% vs $8 \sim 30 \%$ for control)(Figure 4e). Independent of the apical pole size, MRP2 perfectly overlaid the actin structure. However, in the non-polarized phenotypes, MRP2 was diffusively recruited at the contact with the substrate (Figure $\mathbf{4 d , e )}$. Our data demonstrated that the self-organizing process of the cell autonomous hepatic polarity development was orchestrated by the ability of the actin cortex to reorganize from a suspended cortical actin structure into a loose actin meshwork at cell-cell contacts. Engagement of integrin signaling at the basal poles leads to the development of actin fibers at the apical pole. The development of the incorrect actin structure (either by physical impairment or by local absence of cadherin adhesion) led to the inhibition of the apical pole development and all subsequent polarity development.

In conclusion, we have established a novel single cell model to investigate the role of of cell-cell junction in apical basal polarity. Our data demonstrate that the development of apical basal polarity in hepatocytes is a largely cell autonomous 332 process, independent of the nature of their epithelial neighbors. Our results strongly 333 suggest that lumen formation can occur between mature and immature hepatocytes 334 during development. Hepatic polarity appears as an emergent property induced by 335 the spatially segregated contact of cadherin and ECM adhesion without any need for collective cellular response. The structural and mechanical properties of the actin cortex at the lateral contact acts as a switch triggering the development of the apical 
bioRxiv preprint doi: https://doi.org/10.1101/636654; this version posted May 15,2019 . The copyright holder for this preprint (which was

not certified by peer review) is the author/funder, who has granted bioRxiv a license to display the preprint in perpetuity. It is made available under aCC-BY-NC-ND 4.0 International license.

338 pole. The density and spatial distribution of cadherins at the initial cell-cell junction

339 largely regulates the development of an apical actin cortex that in turn drives the 340 polarized organization of the whole cell including that of the Golgi apparatus.

341 Our reductionist approach demonstrate that single hepatocytes can be fooled into a 342 polarized state by artificial microniches and thus constitutes, as far as bile secretion 343 is concerned, the first realization of a single cell liver.

344

345 
Methods:

\section{Microwell fabrication}

Microwells with dimensions of $25 \mu \mathrm{m}$ in diameter and $25 \mu \mathrm{m}$ in height were fabricated using an established method (29). The functionalization of the microwell top, side, and bottom surfaces was achieved by coating with $10 \mu \mathrm{g} / \mathrm{ml}$ fibronectin (Sigma, P1141) for 1hour, followed by flipping into a fibronectin coated coverslip to passivate the new-top surface with a solution of $0.2 \%$ pluronic acid (Sigma, P2443250G).

\section{Generation of Micropatterned substrates}

The 2D patterns were generated by microserigraphy method (30). $100 \mu \mathrm{l}$ of $10 \mu \mathrm{g} / \mathrm{ml}$ fibronectin or E-Cadherin (R\&D System, 8875-EC) was applied to a $2 \times 2 \mathrm{~cm}$ NoA 74 membrane on a polymer bottom dish (ibidi, 81156), and incubated overnight at $4^{\circ} \mathrm{C}$. The membrane was peeled off right before usage and the dish was treated with $0.2 \%$ pluronic acid for $30 \mathrm{~min}$ at RT.

Employing the Alveole PRIMO system, E-Cadherin coated doughnut patterns were produced as recommended by the vendor. $10 \mu \mathrm{l}$ of $100 \mu \mathrm{g} / \mathrm{ml} \mathrm{E}$-Cadherin solution was applied to each PDMS stencil, incubated for 2 hours at room temperature before rinsing with PBS 3 times. The dish was then treated with $0.2 \%$ pluronic acid for $30 \mathrm{~min}$.

\section{Topographical obstacles fabrication:}

Replicas of silicon molds containing the different features (750nm in height) was made by double-casting PDMS (mixed at 10:1 base and curing agent, Sylgard184, Dow Corning) cured at $80^{\circ} \mathrm{C}$ for 3 hours, passivated overnight at low pressure with a solution of Trichloro(1H,1H,2H,2H-perfluorooctyl)-silane (Sigma, 448931).

The textured substrates were generated by UV curing ( $6 \mathrm{~min}, 185$ and $253 \mathrm{~nm}$, $30 \mathrm{~mW} / \mathrm{cm} 2$, UVO Cleaner 342-220, Jelight) a drop of low refractive index polymer premix (MY134, MyPolymers), sandwiched between a glass coverslip and the PDMS mold, and immersed in water. After peeling off the mold, the features were coated overnight with $10 \mu \mathrm{g} / \mathrm{ml}$ E-cadherin solution ( $\mathrm{RnD}, 8875-\mathrm{EC}-50$ ) in PBS at $4^{\circ} \mathrm{C}$ and washed twice with PBS before cell seeding. 
381 hiPSC-derived hepatic progenitor or hepatocyte-like cells were generated using an established protocol $(18,19,31)$. To generate heterodoublets of iPSC-derived hepatocytes at mature and immature stages, hepatocyte-like cells after 25 days of differentiation were detached and suspended in Hepatozyme medium (Thermo, 17705021), supplemented with Oncostatin M 0.01 mg/ml (Bio-Techne, 295-OM-050) and Hepatocyte Growth Factor $0.05 \mathrm{mg} / \mathrm{ml}$ (Peprotech, 100-39-100) to reach a final cell density of $0.5 * 10^{6}$ cells $/ \mathrm{ml}$. Approximately $1 \mathrm{ml}$ cell suspension was then pipetted onto microwells in a $35 \mathrm{~mm}$ glass bottom dish and placed in an incubator for at least 2 hours to allow cell attachment. Extra cells that were not trapped in the wells were removed by rinsing the dish with PBS buffer. The system was then replenished with fresh culture medium. Cells were left in $5 \% \mathrm{CO}_{2}$ at $37^{\circ} \mathrm{C}$ and $95 \%$ humidity for 1 day to develop polarity.

\section{Hepatocyte isolation, seeding and culturing}

Hepatocytes were isolated from male Wistar rats by a two-step in situ collagenase perfusion method, as previously published (32). Animals were handled according to the IACUC protocol approved by the IACUC committee of the National University of Singapore. With a yield of $>10^{8}$ cells/rat, hepatocyte viability was tested to be $>90 \%$ by Trypan Blue exclusion assay.

399 In order to co-culture primary rat hepatocytes with another epithelial cell line, e.g. $400 \mathrm{MDCK}, \mathrm{EpH} 4, \mathrm{Caco} 2$ in a microwell array, freshly isolated rat hepatocytes (0.5 401 million) were seeded onto the microwell in the glass bottom dish and cultured in 2 $402 \mathrm{ml}$ of William's E culture medium supplemented with $2 \mathrm{mM}$ L-Glutamine, $1 \mathrm{mg} / \mathrm{ml}$ $403 \mathrm{BSA}, 0.3 \mu \mathrm{g} / \mathrm{ml}$ of insulin, $100 \mathrm{nM}$ dexamethasone, $50 \mu \mathrm{g} / \mathrm{ml}$ linoleic acid, 100 404 units $/ \mathrm{ml}$ penicillin, and $100 \mathrm{mg} / \mathrm{ml}$ streptomycin (Sigma-Aldrich). After 1 hour 405 incubation, the floating hepatocytes were removed by washing with PBS buffer and 406 culture medium were replenished. 0.5 million MDCK cells expressing histone-GFP 407 (generous gift from Dr Benoit Ladoux, Institut Jacques Monod, Paris), EpH4 or Caco2 408 cells stained with CellTracker ${ }^{T M}$ Green CMFDA Dye (ThermoFisher, C2925) following 409 manufacturer's instruction were subsequently detached and seeded into the 410 microniches. After 1 hour incubation, excess cells were removed and culture 
411 medium were replenished. The system was left in incubator for 24 hours to develop

412 polarity.

413 For micropatterning experiments, 0.5 million rat hepatocytes were added onto E-

414 Cadherin coated micropatterns in a $35 \mathrm{~mm}$ glass bottom dish and cultured in $2 \mathrm{ml}$ of

415 William's E medium with all seven supplements as described before. Cells were 416 incubated with $5 \% \mathrm{CO}_{2}$ at $37^{\circ} \mathrm{C}$ and $95 \%$ humidity. After a 3-hour incubation, the 417 system was rinsed with PBS medium to remove hepatocytes that did not attach to 418 the micropatterns. The petri dish was subsequently replenished with fresh culture 419 medium. 3-hours later, the culture medium was replaced by medium supplemented 420 with $6 \%$ matrigel. The matrigel was handled according to the protocol as described 421 previously[Martın-Belmonte, 2013]. The system was then left in incubator for 24 422 hours.

423

\section{Pharmacological treatment}

425 To inhibit actomyosin contractility or block bile acid synthesis, culture medium

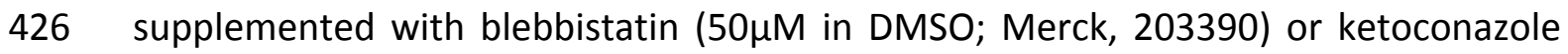
$427(10 \mu \mathrm{M}$ in DMSO; Sigma, K1003) was administered 7 hours after matrigel overlay until 428 cell fixation. To stimulate bile acid secretion, Ursodeoxycholic acid (UDCA, 50 $\mu \mathrm{M}$ in 429 DMSO; Sigma, U5127) was added at the same time as the matrigel overlay.

\section{Immunostaining and image acquisition}

432 Cells were fixed with $4 \%$ paraformaldehyde (PFA) for 30 minutes at $37^{\circ} \mathrm{C}$. After 433 fixation, the cells were rinsed with PBS and permeabilized for $30 \mathrm{~min}$ in PBST $(0.1 \%$ 434 Triton-X diluted in TBS). Permeabilized cells were blocked with 5\% BSA diluted in PBS 435 for $4 \mathrm{~h}$ at $4^{\circ} \mathrm{C}$ and incubated overnight with pan-Cadherin antibody (Sigma, C1821, 436 1:500), MRP2 antibody (Sigma, M8316, 1:200), Par-3 antibody (Millipore, 07-330, 437 1:200), ZO-1 antibody (Life Technology, 61-7300,1:100), ZO-2 antibody 438 (ThermoFisher, 38-9100, 1:100), Claudin-1 antibody (Invitro, 717800, 1:100), 439 Claudin-3 antibody(Abcam, ab15102, 1:40), Occludin antibody (Invitrogen, 711500 440 1:200), MyosinllA antibody (Sigma, M8064, 1:200), Grasp65 antibody(Abcam, $441 \mathrm{ab} 102645,1: 200)$ at $4^{\circ} \mathrm{C}$ as instructed in the manufacturer's protocol. After rinsing 442 with PBS, cells were incubated with secondary antibodies (Alexa Fluor 546 Donkey 
443 Anti-Rabbit IgG, A10040 and Alexa Fluor 647 Donkey Anti-Mouse IgG, A-31571, Life

444 Technologies, 1:200) and Alexa Fluor 488 Phalloidin (Life Technologies, A12379, 445 1:200) or ATTO-565 Phalloidin (Sigma 94072, 1:500) for $1 \mathrm{~h}$ in dark at room 446 temperature. After rinsing with PBS again and incubation with DAPI (Sigma, D9564), 447 cells were mounted in mounting medium (DAKO, S3023). 3D stacks of confocal 448 images were acquired with 60X NA1.3 water lens on a Nikon Eclipse Ti Microscope 449 equipped with Yokogawa CSU-X1 spinning disc unit. Structured Illumination 450 Microscopy images was acquired on the same microscope equipped with Live-SR 451 module ( https://www.cairn-research.co.uk/product/live-sr/). The cells were chosen 452 purely based on criteria of cell adhesion. Typically, more than $70 \%$ of patterns 453 contained single cells that occupied the entire pattern, and these were selected for 454 imaging.

455

\section{RICM analysis:}

RICM analysis was performed considering the theory of partial coherent light, following the description of cell adhesion analyses reported in Limozin and Sengupta (25). Relative heights were reconstructed using the intensity-height relation

$$
I(h)=\frac{S}{2}-D \frac{\sin (y)}{2 y} \cos \left(2 k n_{1}\left[h \cos ^{2}\left(\frac{\alpha}{2}\right)-h_{\mathrm{off}}\right]\right)
$$

where $y=2 k h \sin ^{2}\left(\frac{\alpha}{2}\right)$.

$k=2 \pi / \lambda$ is the wave vector for the illumination light for a wavelength $\lambda=546 \pm$ $10 \mathrm{~nm}, \mathrm{n} 1=1.335$ is the refractive index of the outer buffer, $\mathrm{S}$ and $\mathrm{D}$ are the sum and difference of the maximal and minimal intensity in the experimental fringe pattern, respectively, and $h_{\text {off }}$ is a phase shift arising from the reflection at different interfaces.

The illumination numerical aperture (INA), which is given by the half-angle of the cone of illumination, $\alpha$, was set to a maximum value to minimize the depth of focus and thereby to avoid reflections from organelles or other intracellular structures. The measured INA amounted to INA $=\mathrm{n}_{1} \sin (\alpha)=0.73$. Cell contact areas of constant dark intensity were considered 'adhered' and of clostest proximity to the 
474 substrate. These areas served as starting point for the reconstruction of relative

475 membrane heights.

476 Data were analyzed using self-written routines in Matlab (version 9.3 (R2017b), The

477 MathWorks, Inc. MA, USA) and FIJI (version 1.52s, Rasband, W.S., NIH, Bethesda,MD, 478 USA).

\section{Image analysis}

482 To analyze the relative position of each protein, a homemade program was written 483 with Matlab (MathWorks, Natick, Mass). The position of the lumen center was 484 determined by using fit-circle function implemented in Matlab with a radius range 485 lower than the cell size on the thresholded actin image by Otsu's method acquired at 486 the membrane/substrate interface. The radial profile was then performed on every 487 channel. The intensity profile for each cell was then aligned by normalizing the 488 distance between the centre of the lumen and the outer point of the actin ring. This 489 outer point was determined by finding the maximum of the second derivative of the 490 actin intensity profile. As there was no ring formed on E-cadherin doughnut pattern, 491 the distance was normalized between the centre of the pattern and the inner border 492 of the adhesive area. The relative distance of the different ring was then calculated 493 by measuring the distance between the peaks of the average curve of each staining.

495 To assess Golgi localization in relation to lumen position, the degree of overlay of 496 these two structures was measured. Z direction maximum intensity projection was 497 applied to all the stacks containing Grasp65 signal to extract Golgi structure, while 498 projection of selected frames of Phalloidin staining at the cell/substrate interface 499 was used to extract lumen localization. ROIs of Golgi and lumen structures were 500 created by thresholding the corresponding Z-projection images. The ratio of the 501 number of pixels of the intersection over that of actin mask was finally used to 502 describe the degree of overlaying.

$$
\operatorname{Overlay}(\text { Actin, Golgi })=\frac{\text { Mask }_{\text {Actin }} \cap \text { Mask }_{\text {Golgi }}}{\operatorname{Mask}_{\text {Actin }}}
$$


504 To measure the size and circularity of hemi-lumens and cells, 3 frames of phalloidin

505 staining images at the hepatocyte/substrate interface were selected and

506 reconstructed using maximum intensity projection. The contour of the hemi-lumen

507 and cells was drawn manually based on F-actin signal using ImageJ. The Area and

508 Circularity were measured with the ImageJ measurement plugin. A circularity of 1.0

509 indicates a perfect circle. As the value approaches 0 , it indicates an elongated 510 polygon.

512 To evaluate the MRP2 distribution and actin structure size for hepatocytes cultured 513 on textured substrate, selected frames imaged at the hepatocyte/substrate interface 514 were reconstructed using maximum intensity projection. The areas of MRP2, actin 515 structure and cells were then manually measured using ImageJ.

516

517 Statistical analysis was performed using GraphPad Prism 6 518 (https://www.graphpad.com/scientific-software/prism/). The statistical significance 519 between two groups was analyzed by Unpaired Student's t-test unless otherwise 520 stated. In all cases, a P value of less than 0.05 was considered statistically significant 521 and $P$ value is specified in each captions.

522 


\section{References}

537 1. H. G. Hall, D. A. Farson, M. J. Bissell, Lumen formation by epithelial cell lines

538

539

540

541

542

543

544

545

546

547

548

549

550

551

552

553

554

555

556

557

558

559

560

561

562

563

564

565

566

567

568

569

570

571

572

573

574

575

576

577

578

579

580 in response to collagen overlay: a morphogenetic model in culture. Proceedings of the National Academy of Sciences of the United States of America 79, 4672-4676 (1982).

2. N. Akhtar, C. H. Streuli, An integrin-ILK-microtubule network orients cell polarity and lumen formation in glandular epithelium. Nature cell biology 15, 17-27 (2013).

3. D. M. Bryant, J. Roignot, A. Datta, A. W. Overeem, M. Kim, W. Yu, X. Peng, D. J. Eastburn, A. J. Ewald, Z. Werb, K. E. Mostov, A molecular switch for the orientation of epithelial cell polarization. Developmental cell 31, 171-187 (2014).

4. D. M. Bryant, A. Datta, A. E. Rodríguez-Fraticelli, J. Peränen, F. MartínBelmonte, K. E. Mostov, A molecular network for de novo generation of the apical surface and lumen. Nature cell biology 12, 1035 (2010).

5. E. Rodriguez-Boulan, I. G. Macara, Organization and execution of the epithelial polarity programme. Nature reviews. Molecular cell biology 15, 225-242 (2014).

6. A. E. Rodriguez-Fraticelli, F. Martin-Belmonte, Methods for analysis of apical lumen trafficking using micropatterned 3D systems. Methods in cell biology 118, 105-123 (2013).

7. A. E. Rodriguez-Fraticelli, M. Auzan, M. A. Alonso, M. Bornens, F. MartinBelmonte, Cell confinement controls centrosome positioning and lumen initiation during epithelial morphogenesis. The Journal of cell biology 198, 1011-1023 (2012).

8. A. E. Rodriguez-Fraticelli, F. Martin-Belmonte, Mechanical control of epithelial lumen formation. Small GTPases 4, 136-140 (2013).

9. Q. Li, Y. Zhang, P. Pluchon, J. Robens, K. Herr, M. Mercade, J. P. Thiery, H. Yu, V. Viasnoff, Extracellular matrix scaffolding guides lumen elongation by inducing anisotropic intercellular mechanical tension. Nature cell biology 18, 311-318 (2016).

10. R. Ramanujam, Z. Han, Z. Zhang, P. Kanchanawong, F. Motegi, Establishment of the PAR-1 cortical gradient by the aPKC-PRBH circuit. Nature chemical biology 14, 917-927 (2018).

11. S. C. Wang, T. Y. F. Low, Y. Nishimura, L. Gole, W. Yu, F. Motegi, Cortical forces and CDC-42 control clustering of PAR proteins for Caenorhabditis elegans embryonic polarization. Nature cell biology 19, 988-995 (2017).

12. F. Motegi, S. Zonies, Y. Hao, A. A. Cuenca, E. Griffin, G. Seydoux, Microtubules induce self-organization of polarized PAR domains in Caenorhabditis elegans zygotes. Nature cell biology 13, 1361-1367 (2011).

13. N. Motosugi, T. Bauer, Z. Polanski, D. Solter, T. Hiiragi, Polarity of the mouse embryo is established at blastocyst and is not prepatterned. Genes \& development 19, 1081-1092 (2005).

14. E. J. Y. Kim, E. Korotkevich, T. Hiiragi, Coordination of Cell Polarity, Mechanics and Fate in Tissue Self-organization. Trends in cell biology 28, 541-550 (2018). 
581

582

583

584

585

586

587

588

589

590

591

592

593

594

595

596

597

598

599

600

601

602

603

604

605

606

607

608

609

610

611

612

613

614

615

616

617

618

619

620

621

622

623

624

625

626

627

15. J. Zenker, M. D. White, M. Gasnier, Y. D. Alvarez, H. Y. G. Lim, S. Bissiere, M. Biro, N. Plachta, Expanding Actin Rings Zipper the Mouse Embryo for Blastocyst Formation. Cell 173, 776-791 e717 (2018).

16. J. L. Maitre, H. Turlier, R. Illukkumbura, B. Eismann, R. Niwayama, F. Nedelec, T. Hiiragi, Asymmetric division of contractile domains couples cell positioning and fate specification. Nature 536, 344-348 (2016).

17. A. F. Baas, J. Kuipers, N. N. van der Wel, E. Batlle, H. K. Koerten, P. J. Peters, H. C. Clevers, Complete polarization of single intestinal epithelial cells upon activation of LKB1 by STRAD. Cell 116, 457-466 (2004).

18. S. S. Ng, K. Saeb-Parsy, S. J. I. Blackford, J. M. Segal, M. P. Serra, M. HorcasLopez, D. Y. No, S. Mastoridis, W. Jassem, C. W. Frank, N. J. Cho, H. Nakauchi, J. S. Glenn, S. T. Rashid, Human iPS derived progenitors bioengineered into liver organoids using an inverted colloidal crystal poly (ethylene glycol) scaffold. Biomaterials 182, 299-311 (2018).

19. S. J. I. Blackford, S. S. Ng, J. M. Segal, A. J. F. King, A. L. Austin, D. Kent, J. Moore, M. Sheldon, D. Ilic, A. Dhawan, R. R. Mitry, S. T. Rashid, Validation of Current Good Manufacturing Practice Compliant Human Pluripotent Stem Cell-Derived Hepatocytes for Cell-Based Therapy. Stem cells translational medicine 8, 124-137 (2019).

20. Y. Koui, T. Kido, T. Ito, H. Oyama, S.-W. Chen, Y. Katou, K. Shirahige, A. Miyajima, An In Vitro Human Liver Model by iPSC-Derived Parenchymal and Non-parenchymal Cells. Stem cell reports 9, 490-498 (2017).

21. A. A. Palakkan, J. Nanda, J. A. Ross, Pluripotent stem cells to hepatocytes, the journey so far. Biomedical reports 6, 367-373 (2017).

22. S. S. Bale, S. Geerts, R. Jindal, M. L. Yarmush, Isolation and co-culture of rat parenchymal and non-parenchymal liver cells to evaluate cellular interactions and response. Scientific reports 6, 25329 (2016).

23. J. Gu, X. Shi, Y. Zhang, X. Chu, H. Hang, Y. Ding, Establishment of a threedimensional co-culture system by porcine hepatocytes and bone marrow mesenchymal stem cells in vitro. Hepatology research : the official journal of the Japan Society of Hepatology 39, 398-407 (2009).

24. B. Tsuchiya, Y. Sato, T. Kameya, I. Okayasu, K. Mukai, Differential expression of $\mathrm{N}$-cadherin and E-cadherin in normal human tissues. Archives of histology and cytology 69, 135-145 (2006).

25. L. Limozin, K. Sengupta, Quantitative reflection interference contrast microscopy (RICM) in soft matter and cell adhesion. Chemphyschem : a European journal of chemical physics and physical chemistry 10, 2752-2768 (2009).

26. N. Tsukada, C. A. Ackerley, M. J. Phillips, The structure and organization of the bile canalicular cytoskeleton with special reference to actin and actinbinding proteins. Hepatology 21, 1106-1113 (1995).

27. T. Wang, K. Yanger, B. Z. Stanger, D. Cassio, E. Bi, Cytokinesis defines a spatial landmark for hepatocyte polarization and apical lumen formation. Journal of cell science 127, 2483-2492 (2014).

28. Á. Román-Fernández, J. Roignot, E. Sandilands, M. Nacke, M. A. Mansour, L. McGarry, E. Shanks, K. E. Mostov, D. M. Bryant, The phospholipid PI(3,4)P2 is an apical identity determinant. Nature Communications 9, 5041 (2018). 
29. X. Gao, C. Stoecklin, Y. Zhang, Z. Weng, R. De Mets, G. Grenci, V. Viasnoff, Artificial Microniche Array with Spatially Structured Biochemical Cues. Methods in molecular biology 1771, 55-66 (2018). fabrication of thin membranes with through holes. Application to protein patterning. PloS one 7, e44261 (2012).

31. N. R. F. Hannan, C.-P. Segeritz, T. Touboul, L. Vallier, Production of hepatocyte-like cells from human pluripotent stem cells. Nature protocols $\mathbf{8}$, 430-437 (2013).

637

32. B. Quistorff, J. Dich, N. Grunnet, Preparation of isolated rat liver hepatocytes. Methods in molecular biology 5, 151-160 (1990).

639 
a
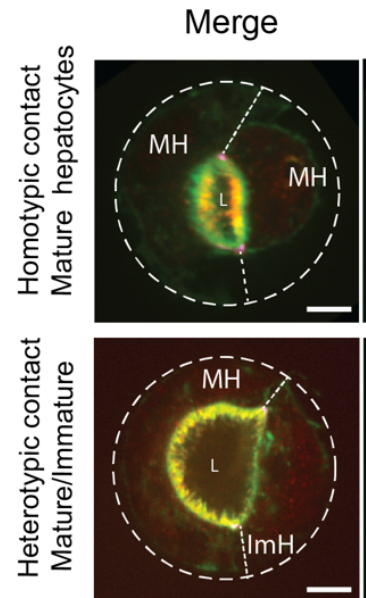

b
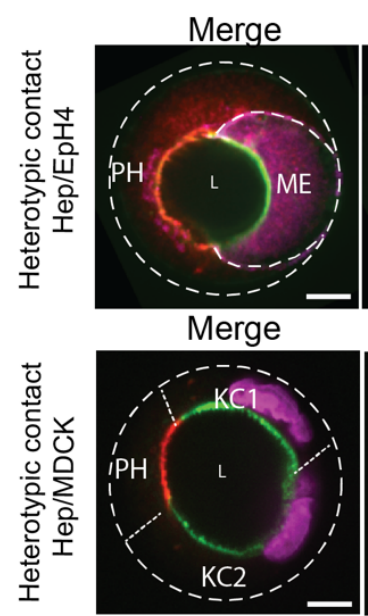

Actin
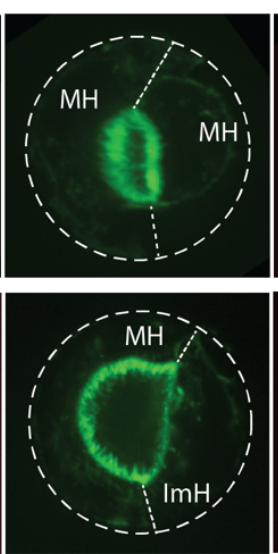

Actin

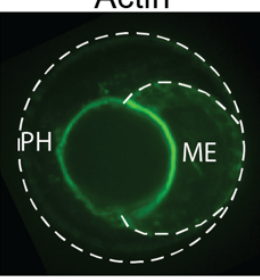

GP135
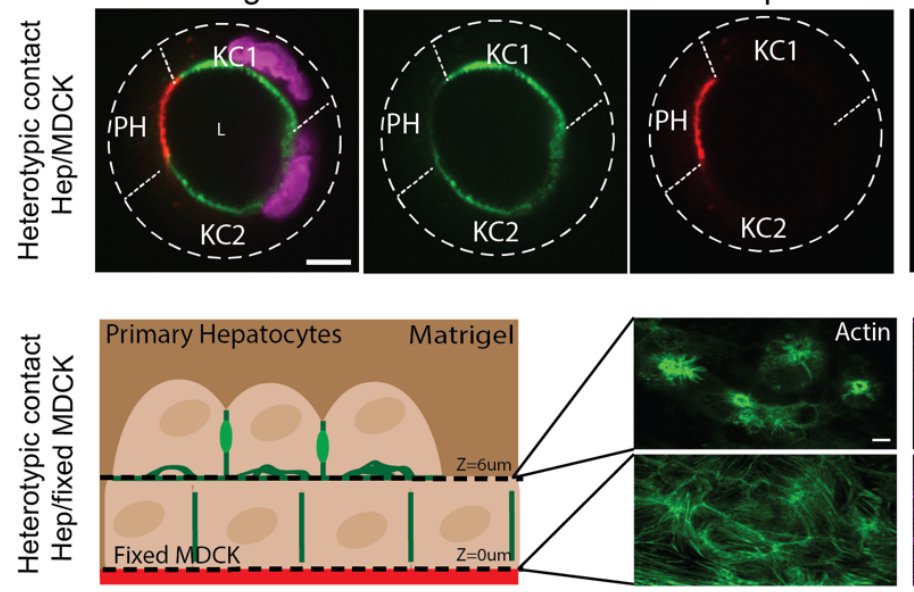

Mrp2
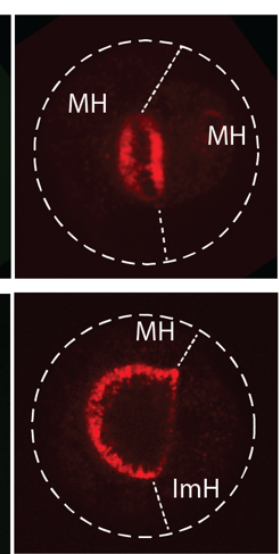

Mrp2

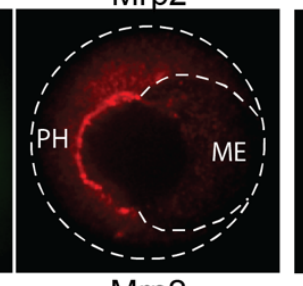

Mrp2
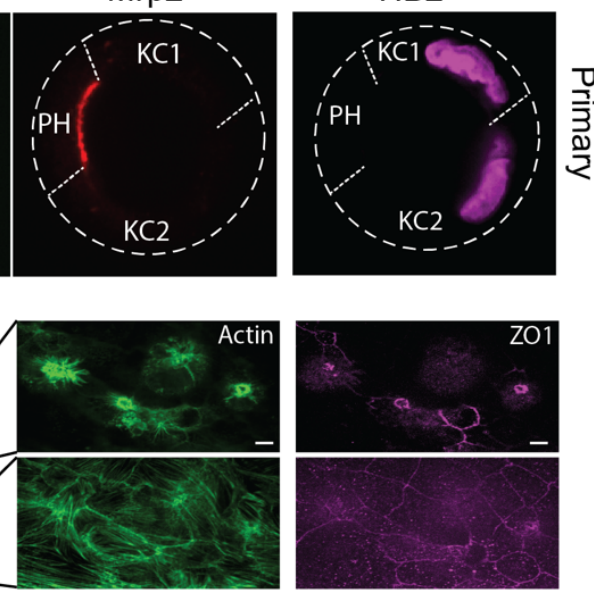

$\mathrm{ZO}-1$
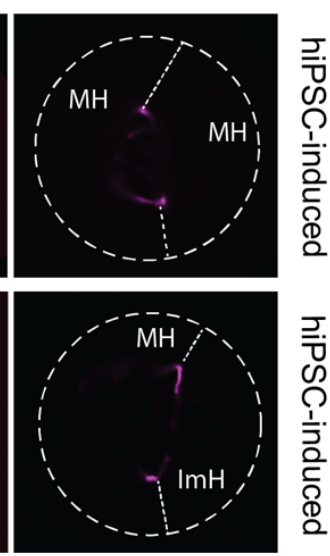

Cell Tracker

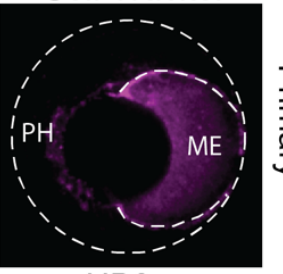

국.

ํㅗㄹ.

d
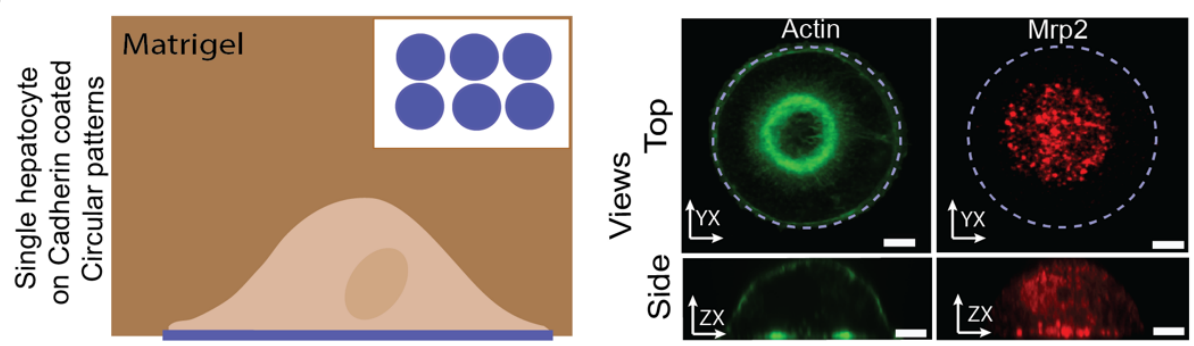

Figure 1 : Hepatocytes are able to form lumens with different types of substrates. a, Overlay of confocal images of the lumen $(L)$ created inside a microwell between mature $(\mathrm{MH})$ and immature hepatocytes $(\mathrm{ImH})$ stained for Actin (green), Mrp2 (red) and ZO-1 (magenta) respectively. The well wall and cell junction has been delimited by dashed lines. Scale bar $=10 \mu \mathrm{m}$. $\mathbf{b}$, Representative confocal images of the lumen lines such as mammary epithelial cells (Eph4, ME) or kidney cells (MDCK, KC) stained 
bioRxiv preprint doi: https://doi.org/10.1101/636654; this version posted May 15,2019 . The copyright holder for this preprint (which was

not certified by peer review) is the author/funder, who has granted bioRxiv a license to display the preprint in perpetuity. It is made available under aCC-BY-NC-ND 4.0 International license.

649 with Mrp2 (red), actin/golgi (green) and cell tracker/histones (magenta). Scale bar = $65010 \mu \mathrm{m}$. c, Left, side view illustration of the co-culture of fixed MDCK with primary 651 hepatocytes. Right, confocal images of actin (green) and ZO-1 circular structures 652 (magenta) at the interface between primary hepatocytes and fixed MDCK $(Z=6 \mu \mathrm{m})$ 653 after $24 \mathrm{~h}$ of seeding, and between fixed MDCK with the coverslip ( $\mathrm{Z}=0 \mu \mathrm{m})$. Scale bar $654=10 \mu \mathrm{m}$. d, Left, Side view illustration of single cell primary hepatocytes. Right, 655 Immunostaining of actin (green) and Mrp2 (red) of primary hepatocytes on an E656 cadherin island covered with matrigel reveal an actin ring located at the interface 657 with the coverslip and a preferential localisation of Mrp2 above the actin ring. Scale 658 bar $=10 \mu \mathrm{m}$. 
bioRxiv preprint doi: https://doi.org/10.1101/636654; this version posted May 15, 2019. The copyright holder for this preprint (which was

not certified by peer review) is the author/funder, who has granted bioRxiv a license to display the preprint in perpetuity. It is made available under aCC-BY-NC-ND 4.0 International license.

a
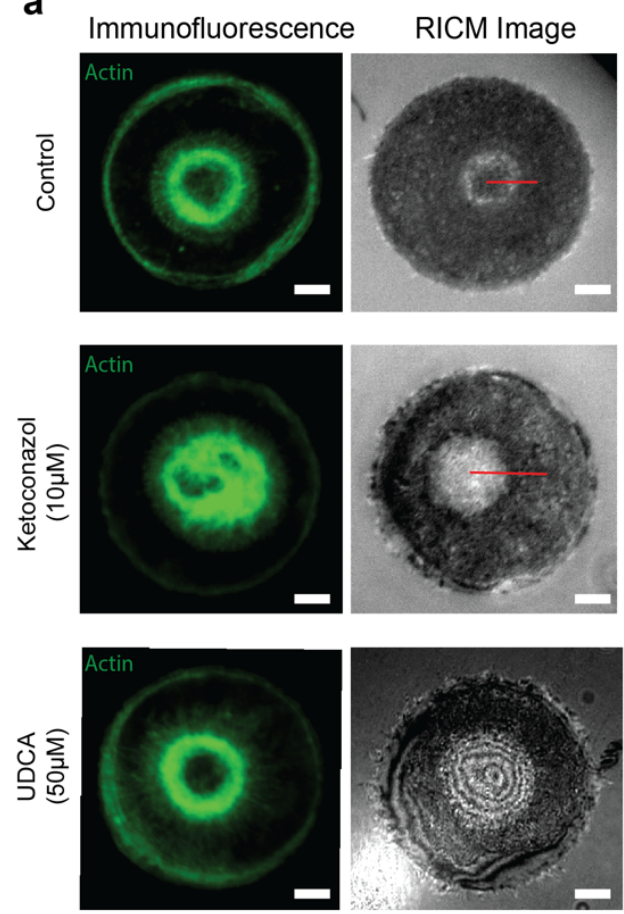

b
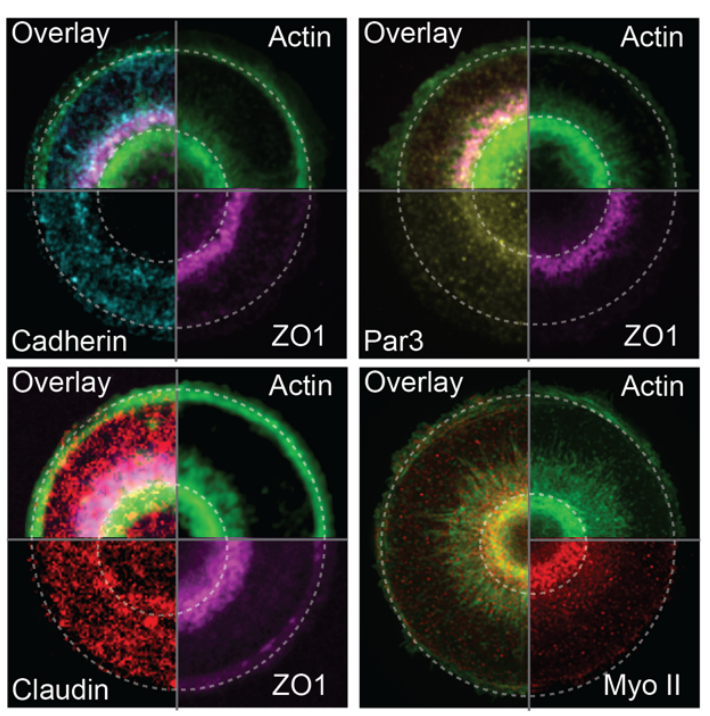

d
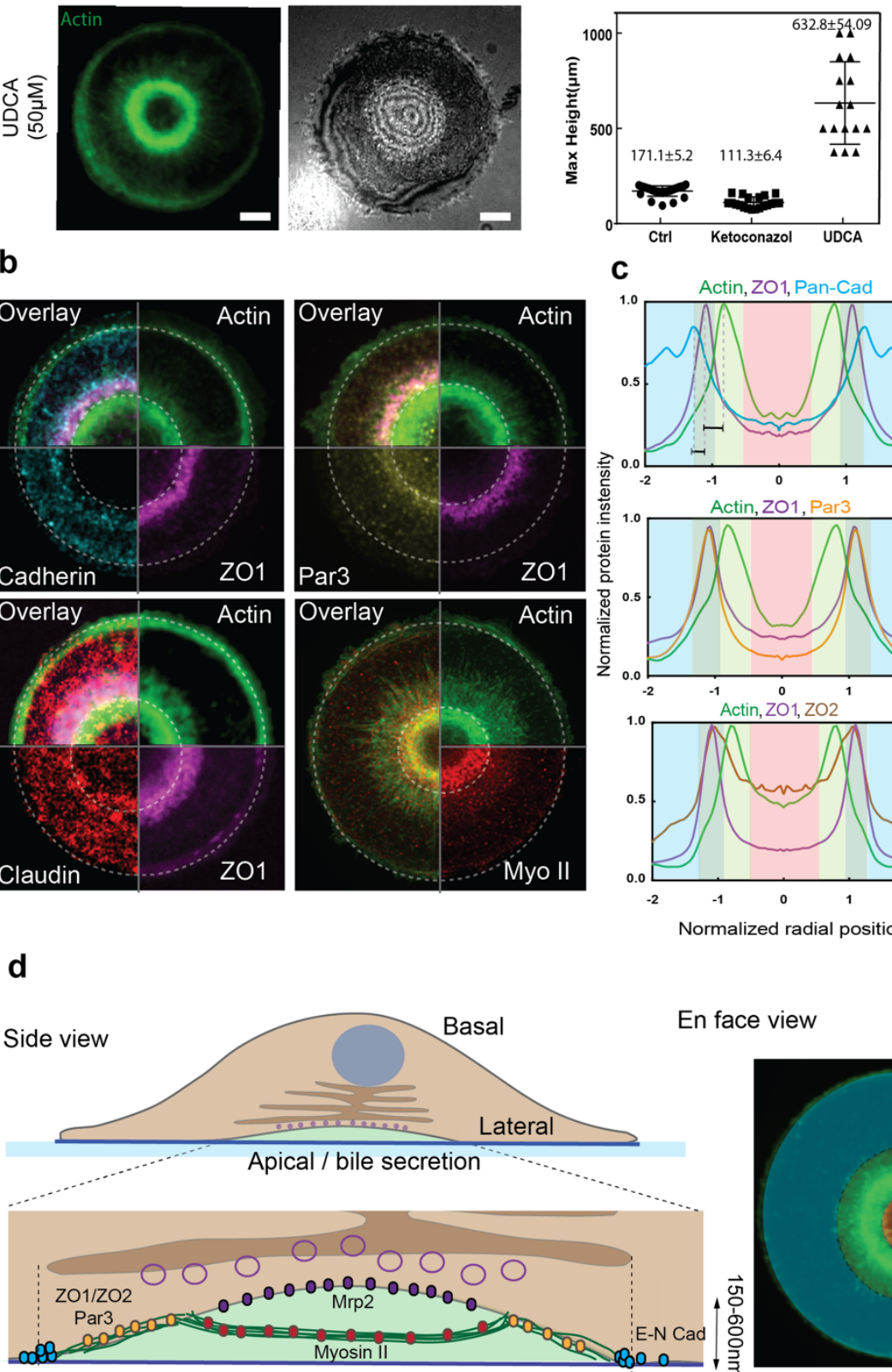

C
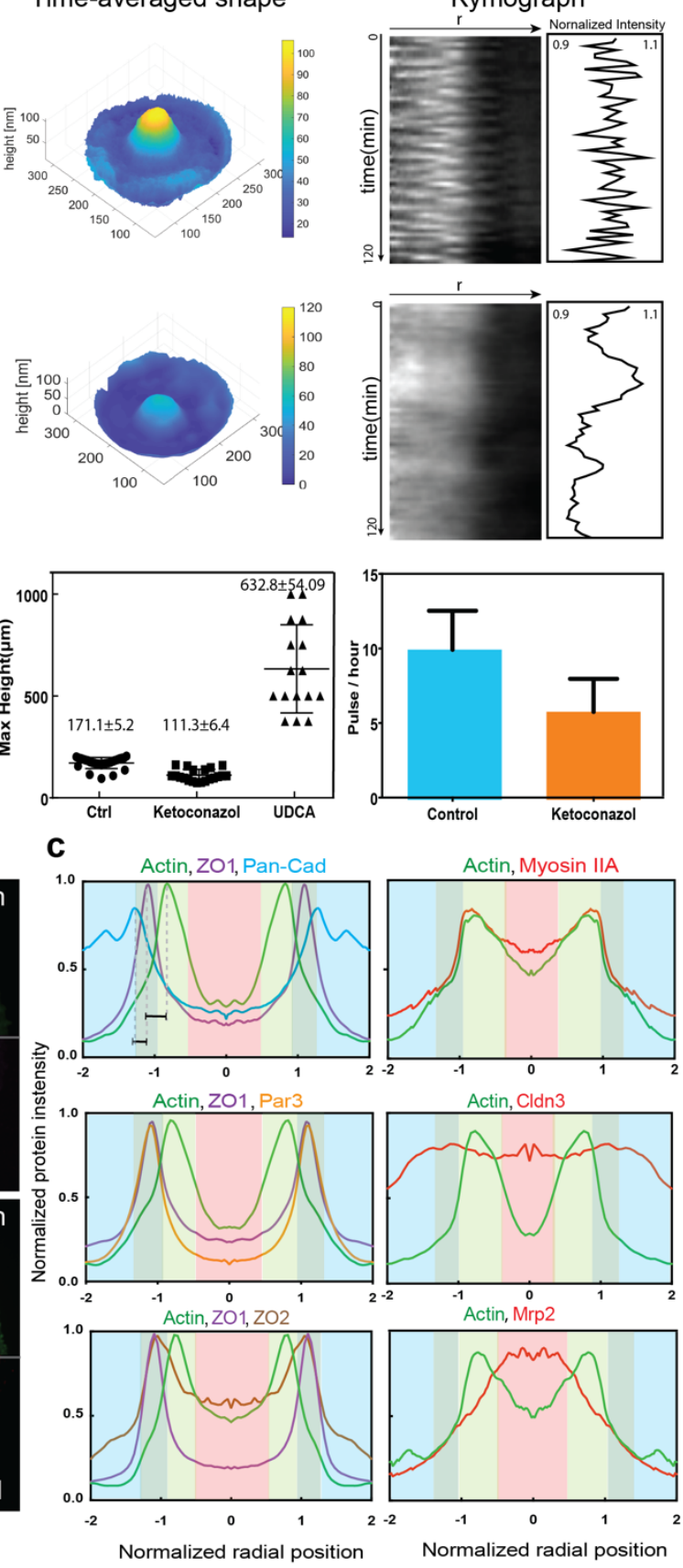

En face view

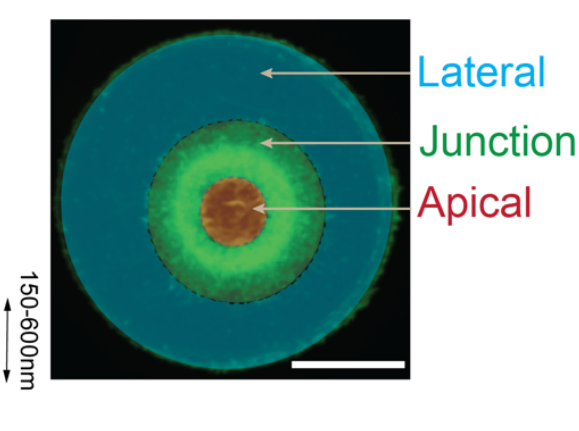


bioRxiv preprint doi: https://doi.org/10.1101/636654; this version posted May 15,2019 . The copyright holder for this preprint (which was

not certified by peer review) is the author/funder, who has granted bioRxiv a license to display the preprint in perpetuity. It is made available under aCC-BY-NC-ND 4.0 International license.

662 Figure 2 : Characterisation of protein organization and behaviour of single-cell 663 hemi-lumen.

664 a, Left, immunostaining and RICM images of single-cell liver following different drug 665 treatments. Right, quantification of height and pulsation behaviour under the three 666 different treatments. Reduction of bile secretion by ketoconazole induces a 667 homogeneous bright circle that is smaller, and with a slow pulsation compared to 668 control. Boosting secretion by UDCA induces an inflation of the lumen resulting in 669 multiple interference rings on the RICM images. $N_{\text {ctrl }}=25, N_{\text {ket }}=20, N_{U D C A}=16$, Scale bar $670=10 \mu \mathrm{m}$. $\mathbf{b}$ and $\mathbf{c}$, Montage and quantification of confocal images of the hemi-lumen 671 stained for structural and polarity markers illustrates the spatial localisation of the 672 different rings of proteins around the lumen. For quantification, the centre of the 673 lumen is considered as 0 while the edge of the actin ring is considered as 1 . The red, 674 dark green, light green and blue background correspond to the region described in $\mathrm{d}$. 675 d, Side and en face view illustration of the position of the different proteins studied 676 and discretisation of the cell-coverslip interface in four regions. The apical pole (red 677 region) is delimited by the actin ring (light green region). As well as containing actin, 678 this inner ring is rich in myosin IIA. Moving outwards, rings of ZO1/ZO2 and Par3 are 679 found (dark green region, followed by cell-cell contacts labelled by E-cadherin (blue 680 region). E-cadherin is not observed from the centre of the lumen out to the ZO1/ZO2 681 ring. Mrp2 is mostly located above the apical pole. In this system, claudins did not 682 exhibit any specific localisation. Scale bar $=20 \mu \mathrm{m}, \mathrm{N}_{\text {ActZO1Cad }}=9, \mathrm{~N}_{\text {ActMyosin }}=14$, 683 $\mathrm{N}_{\text {ActZO1Par3 }}=17, \mathrm{~N}_{\text {ActCldn3 }}=10, \mathrm{~N}_{\text {ActZO1ZO2 }}=5, \mathrm{~N}_{\text {ActMrp2 }}=11$. 


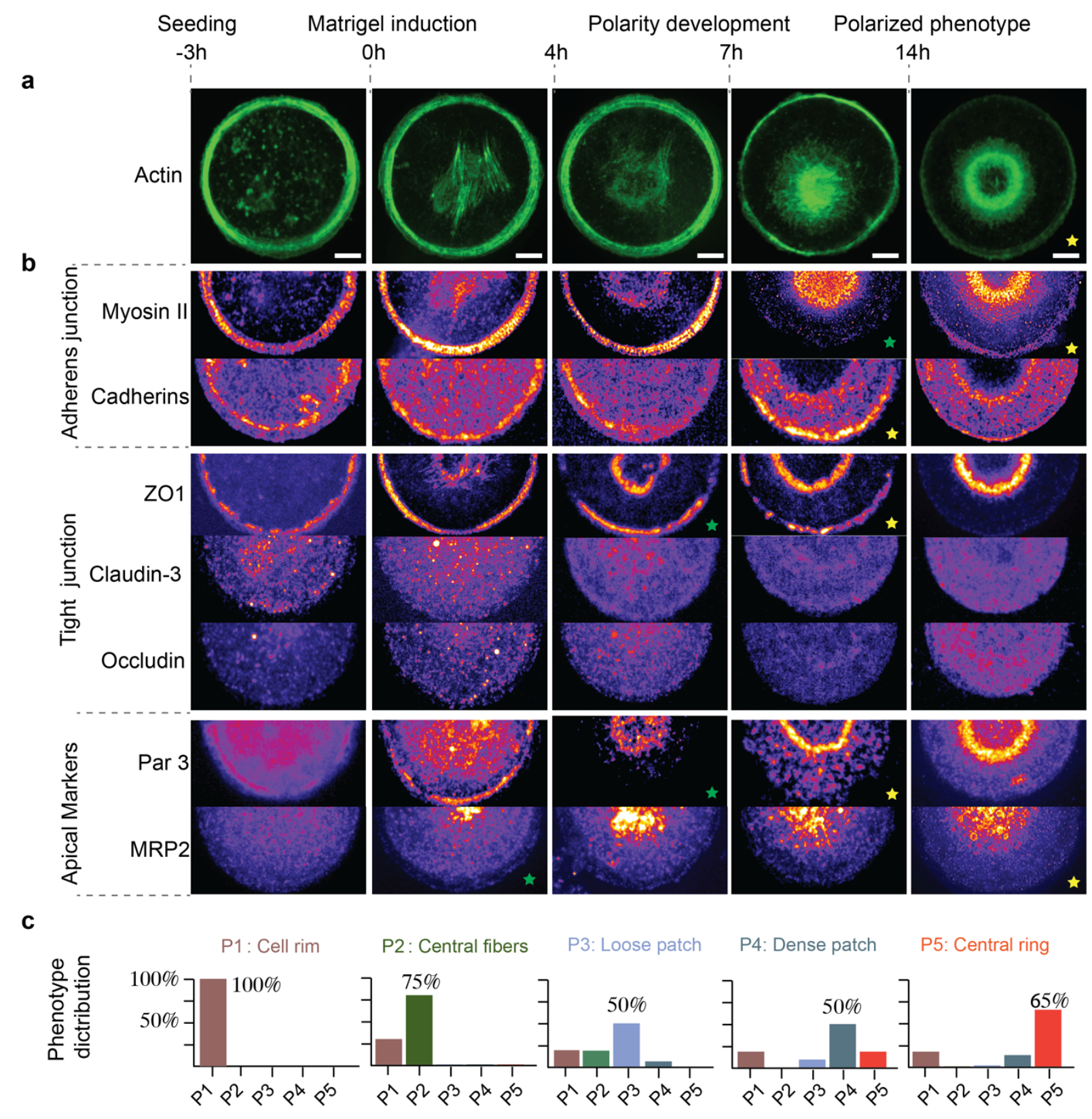
reorganization throughout polarity establishment.

689 a, Representative Structured Illumination Microscopy (SIM) images showing the 690 formation of an actin ring around the apical pole of single hepatocytes situated on Ecadherin circular patterns fixed at 3 hours before, and then $0,4,7,10$ and 14 hours after matrigel addition. Scale bar, $5 \mu \mathrm{m}$. b, Representative SIM images of adherens junction associated proteins (Cadherins and Myosin II), cytosolic and transmembrane components of tight junction (ZO-1, claudin-3 and, occludin), apical markers (Par3 and MRP2) at five stages of polarity development. c, Fraction of cells displaying typical phenotypes of each development phase fixed at different time points. Based on the actin organization, five phases are defined as indicated. The number of cells analyzed was pooled from $n=3$ independent experiments ( $N=42$ for $P 1, N=65$ for $\mathrm{P} 2, \mathrm{~N}=56$ for $\mathrm{P} 3, \mathrm{~N}=66$ for $\mathrm{P} 4, \mathrm{~N}=72$ for $\mathrm{P} 5$ ). 
bioRxiv preprint doi: https://doi.org/10.1101/636654; this version posted May 15,2019 . The copyright holder for this preprint (which was

not certified by peer review) is the author/funder, who has granted bioRxiv a license to display the preprint in perpetuity. It is made available under aCC-BY-NC-ND 4.0 International license. 


\section{a}
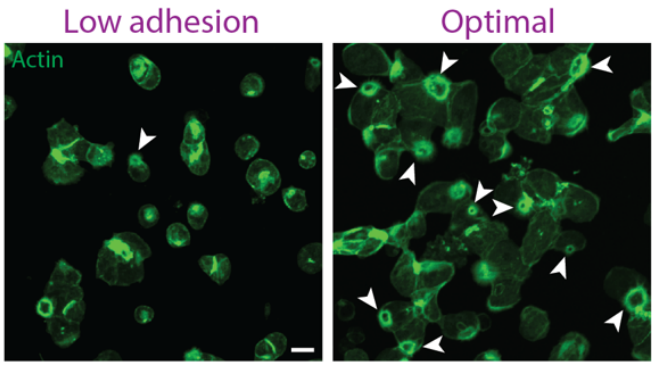

b

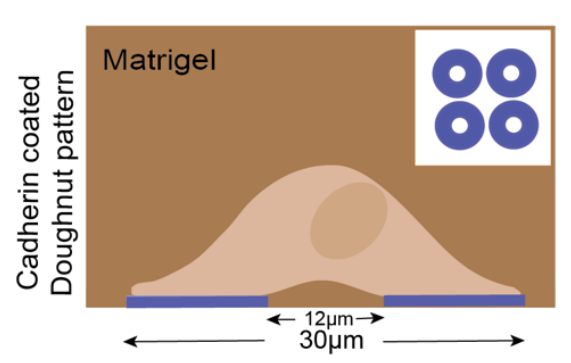

C
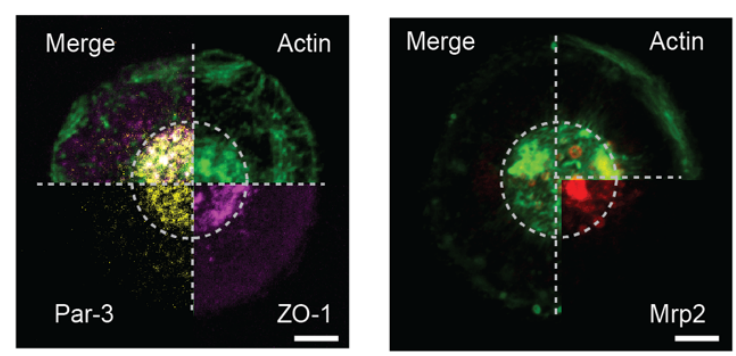

Actin/MRP2/ZO-1

d

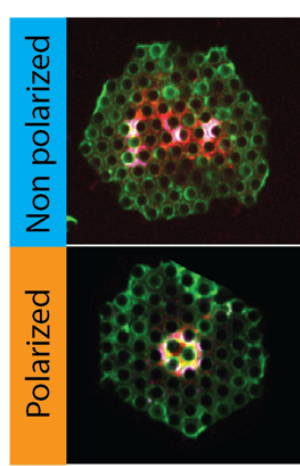

MicroPillar

e

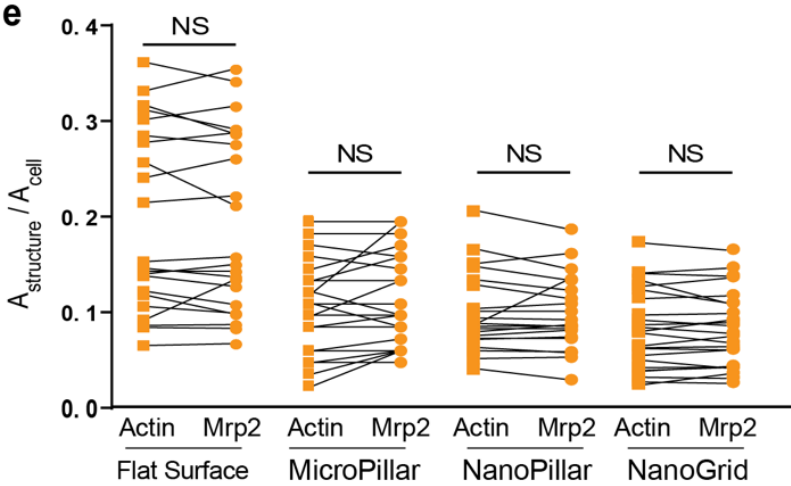

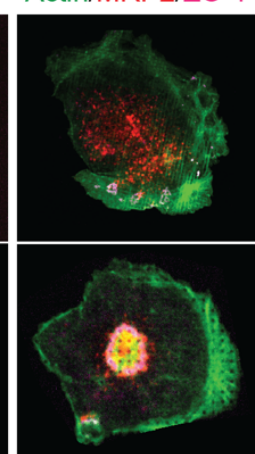

NanoPillar

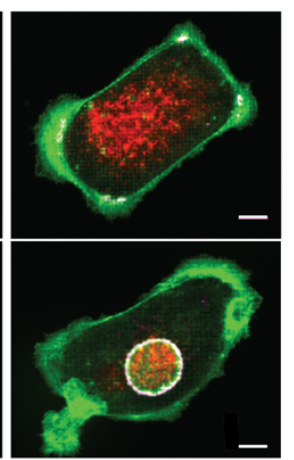

NanoGrid
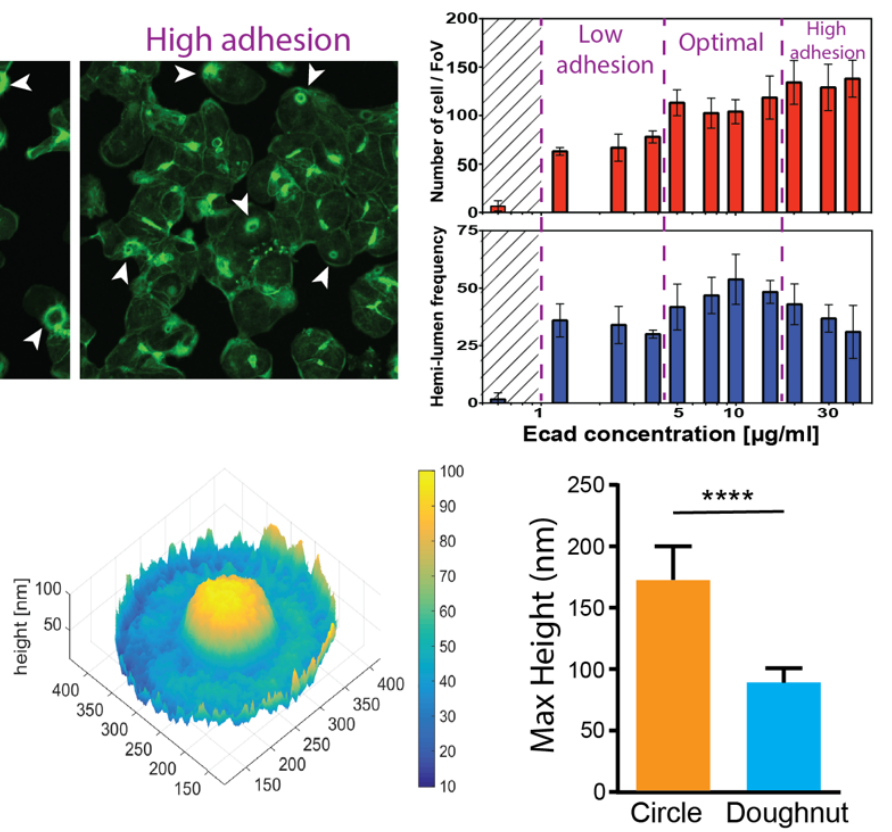
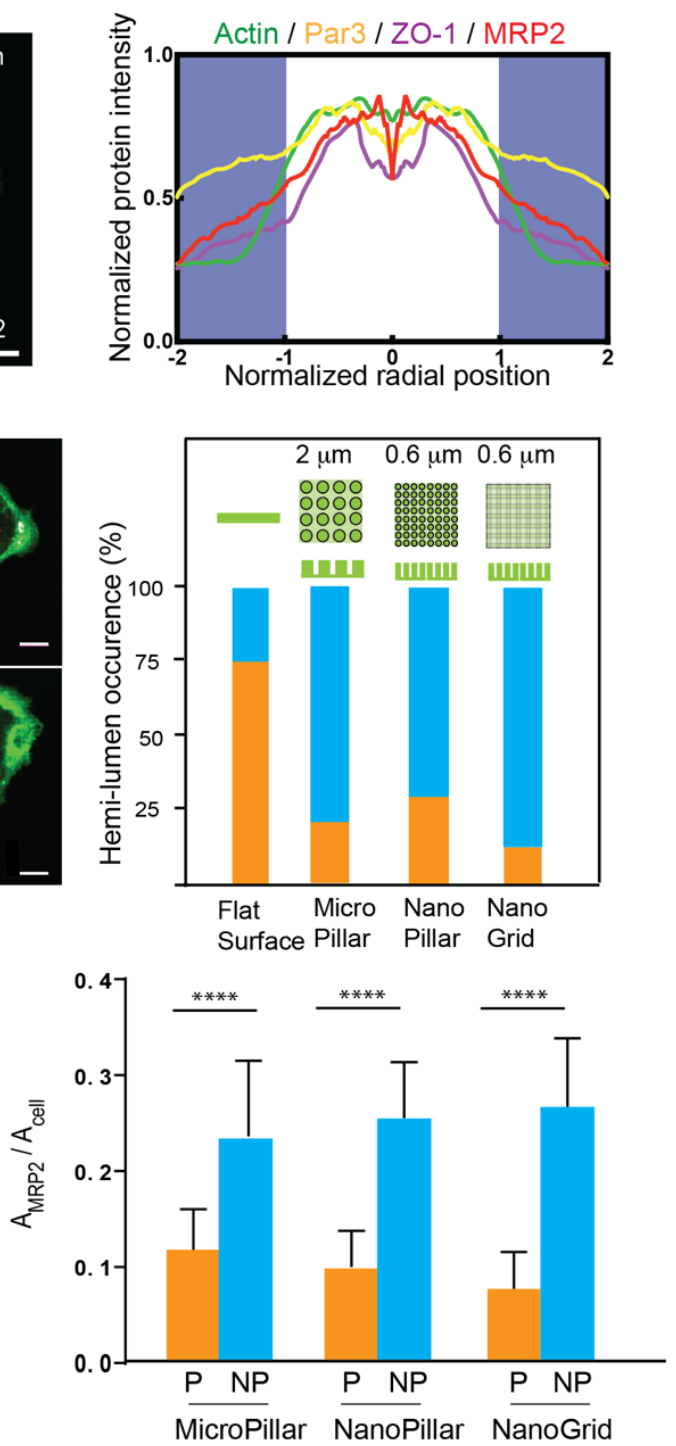
704

705

706

707

708

709

710

711

712

713

714

715

716

717

718

719

720

721

722

723

724

725

726

727

728

729

730

731

732

733

734

735

736

737

738

739

740

741

742

743

744

745

Figure 4 : Cadherin-distribution-dependent actin organization is critical for apicobasal polarity establishment.

a, Low magnification images of primary hepatocytes stained for actin after seeding on different concentrations of E-cadherin. A minimum threshold of E-cadherin concentration is required for the cells to attach, illustrated by the shaded region on the right graph. The number of cells attaching increases with the concentration of Ecadherin above this threshold value. The frequency of hemi-lumen formation reaches an optimum at $10 \mu \mathrm{g} / \mathrm{ml}$ E-cadherin, above which the cells preferentially form lumens between each other. White arrows point to representative hemilumens. Experiments have been performed on 12 fields of views in 4 independent experiments for each concentration. Scale bar, $10 \mu \mathrm{m}$. b, Left panel: Schematic of the geometry and dimensions of the E-cadherin coated doughnut pattern. Middle panel: Representative heat map showing the height of plasma membrane to the coverslip measured from reflective interference contrast microscopy (RICM) image on doughnut pattern of e-cadherin. Right panel: Maximum height of plasma membrane quantified from RICM images of primary hepatocytes on E-cadherin circular $(n=28)$ and doughnut $(\mathrm{n}=14)$ patterns. ${ }^{* * * *}, \mathrm{p}<0.0001$. c, Representative fluorescence images showing the actin, ZO-1, Par3 (left) and actin, MRP2 (middle) localized on the plasma membrane/E-cadherin interface. Scale bar: $5 \mu \mathrm{m}$. Quantification of actin, ZO1, Par3, MRP2 distribution in relation to the position of the non-adhesive region (white) and E-cadherin coated region (Purple), $n=16$ for cells stained with actin, ZO-1 and Par3, $\mathrm{n}=11$ for cells stained with actin and MRP2. Despite the creation of a lumen-like structure on doughnut pattern, no specific localization of apical markers has been identified.

d, Representative immunofluorescence images showing perturbation of Actin, MRP2 and ZO-1 distribution in hepatocytes with either a disorganized central actin phenotype (top, non-polarized NP) or with central actin ring phenotype (below, polarized P) when seeded on micropillar, nanopillar, and nanogrid substrates coated with E-cadherin. Scale bar, $5 \mu \mathrm{m}$. Quantification of hemi-lumen occurrence in cells on flat surface and on textured substrates as indicated $(N=53,82,81$ and 100 for flat, micropillar, nanopillar, and nanogrid, respectively). Schematics show the dimension of each texture. The number of cells analyzed was pooled from 4 independent experiments.

e, Quantification of the ratio of the area of the central actin ring and MRP2 ( $A_{\text {structure }}$ ) to the cell area $\left(A_{\text {cell }}\right)$ for polarized primary hepatocytes seeded on flat surface $(n=22)$, micropillar $(n=25)$, nanopillar $(n=20)$ and nanogrid $(n=24)$. Black lines pair the ratio measured for actin and MRP2 in the same hepatocyte. Quantification of the ratio of the area of MRP2 to the cell area of polarized (P) and non-polarized cells (NP) seeding on micropillar, nanopillar and nanogrid ( $n=24-35), * * * *, p<0.0001$. 
bioRxiv preprint doi: https://doi.org/10.1101/636654; this version posted May 15, 2019. The copyright holder for this preprint (which was

not certified by peer review) is the author/funder, who has granted bioRxiv a license to display the preprint in perpetuity. It is made available under aCC-BY-NC-ND 4.0 International license.

749 Autonomous induction of hepatic polarity to construct single cell liver.

750 Yue Zhang ${ }^{1}$, Richard de Mets ${ }^{1}$, Cornelia Monzel ${ }^{2}$, Pearlyn Toh ${ }^{1}$, Noemi Van Hul ${ }^{3,4}$,

751 Soon Seng $\mathrm{Ng}^{5}$, S.Tamir Rashid ${ }^{5,6}$, Virgile Viasnoff ${ }^{1,7,8}$

752

753

754

a

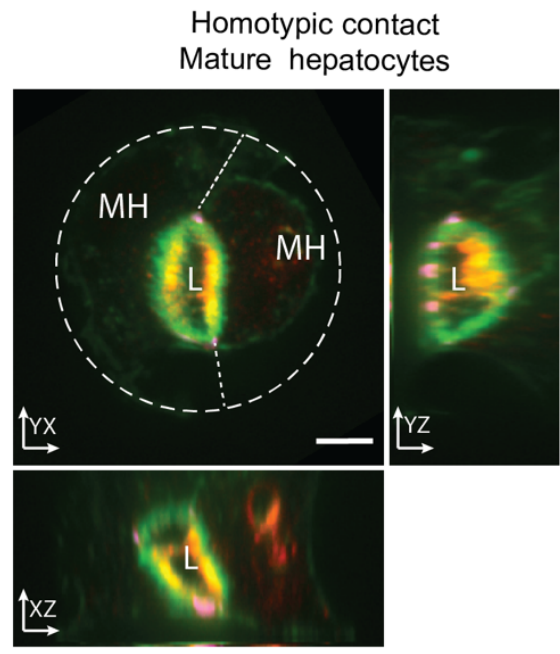

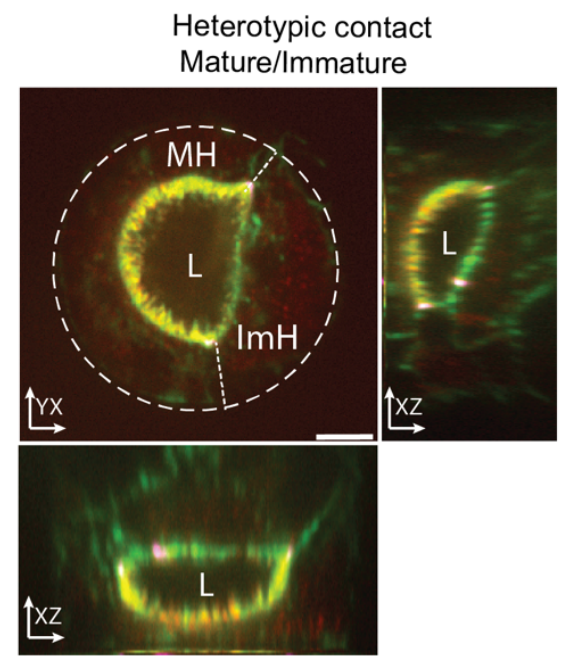

b

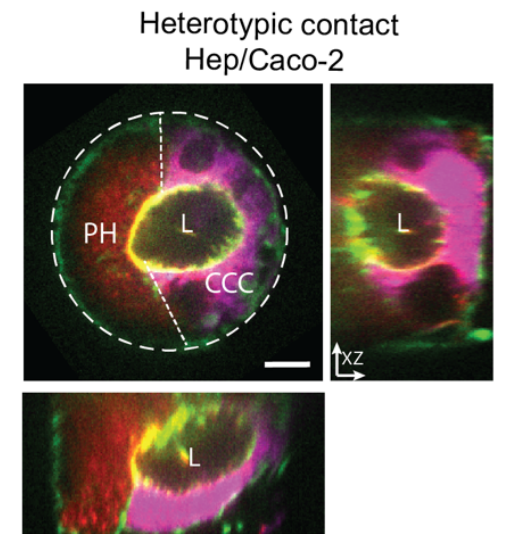

Heterotypic contact $\mathrm{Hep} / \mathrm{EpH} 4+$

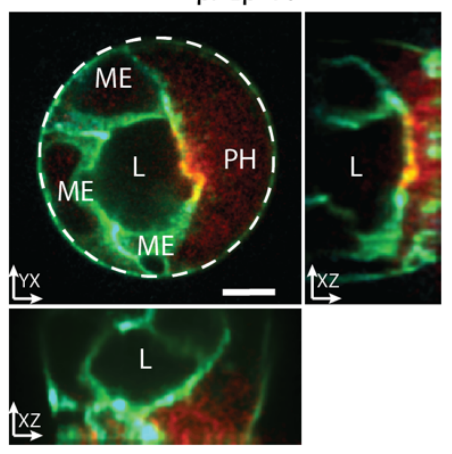

Heterotypic contact Hep/MDCK

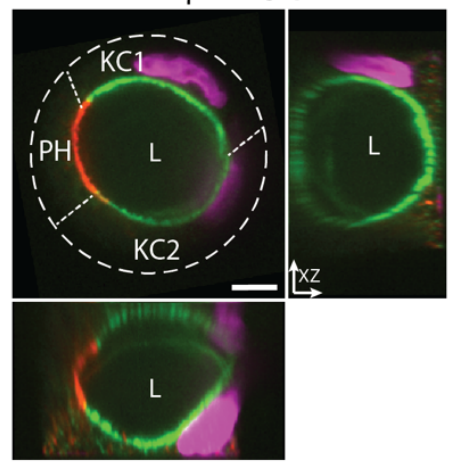

Heterotypic contact

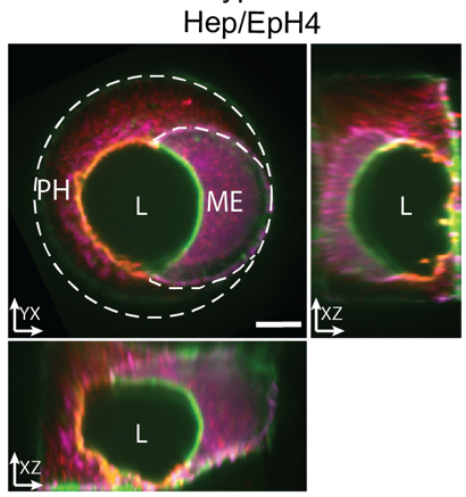

Caco2 Eph4+ Eph4 MDCK
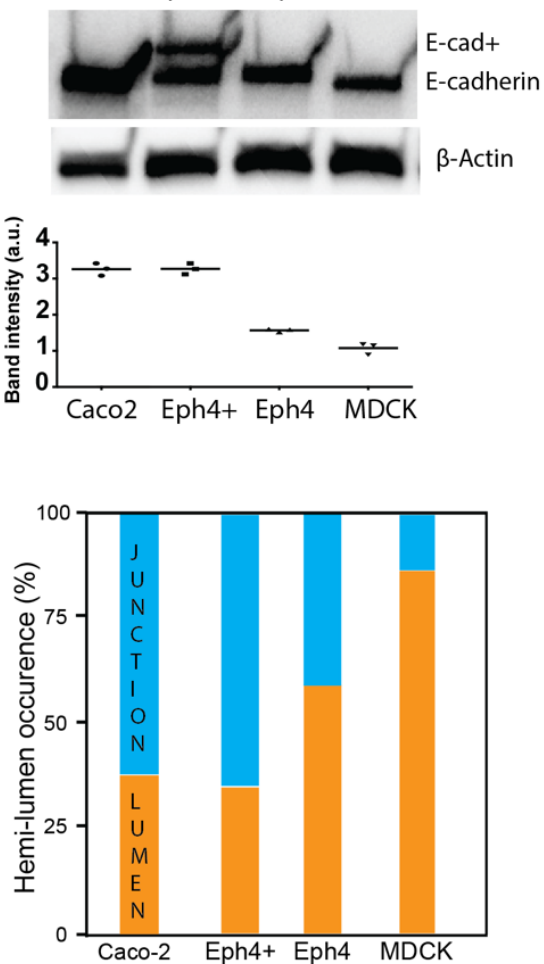
bioRxiv preprint doi: https://doi.org/10.1101/636654; this version posted May 15,2019 . The copyright holder for this preprint (which was

not certified by peer review) is the author/funder, who has granted bioRxiv a license to display the preprint in perpetuity. It is made available under aCC-BY-NC-ND 4.0 International license.

\section{Supplementary Figure 1:}

757 Orthogonal views of heterodoublets forming lumen-like structures. a, Orthogonal 758 views of representative images for Figure 1 showing lumens formed between mature 759 (MH) and immature (ImH) hiPSC derived hepatocyte. MRP2 (red) is exclusively 760 recruited to the apical domain of mature hepatocytes. Dash lines indicate the cell761 cell contacts. b, Top and side views of heterodoublets between primary rat 762 hepatocytes (PH) and different epithelial cell lines (MDCK, Eph4, EPH4+Ecad,Caco2). 763 Discrimination between cell types was performed using prestaining before the 764 formation of the doublets. Caco2 and Eph4 cell lines were pre stained using cell 765 tracker, Eph4+ expressed E-cad GFP and Actin is in green, MDCK expressed H2B-GFP. 766 E-cadherin levels in each cell lines were assessed by three indepednetn westernblot. 767 The hemi-lumen occurrence is inversely correlated to expression levels of E768 cadherin. Scale bar, $5 \mu \mathrm{m} . \quad \mathrm{N}_{\mathrm{Caco} 2}=29(38 \%), \quad \mathrm{N}_{\mathrm{Eph} 4+}=20(35 \%), \quad \mathrm{N}_{\text {Eph4 }}=56$ (59\%), $769 \mathrm{~N}_{\mathrm{MDCK}}=53(87 \%)$, 
a

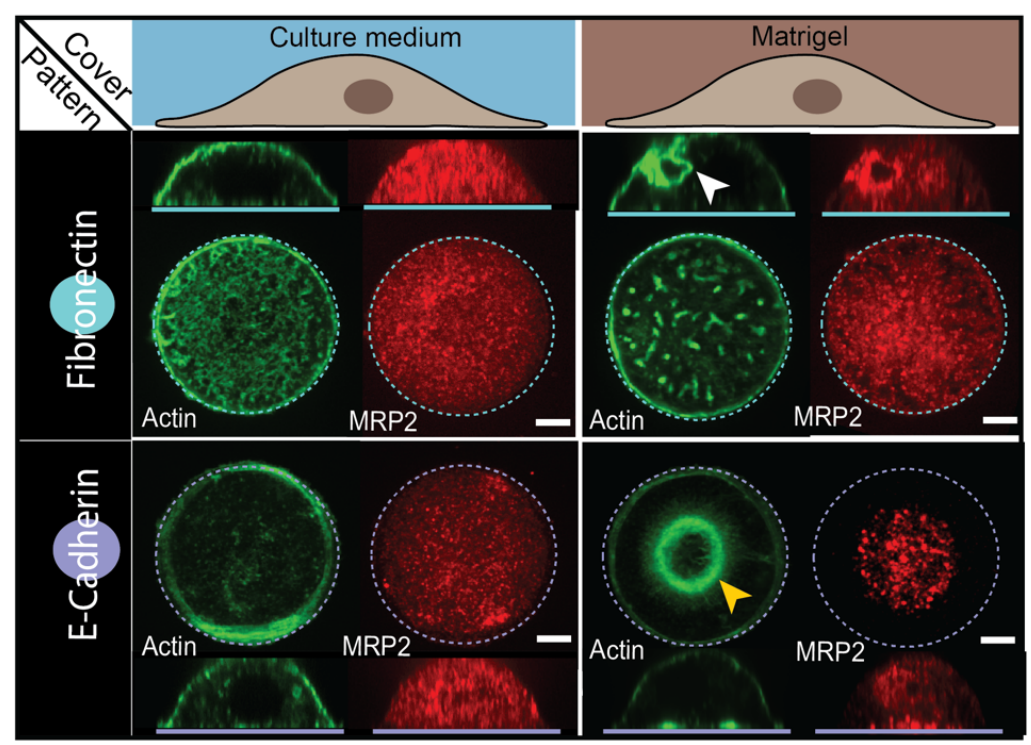

b

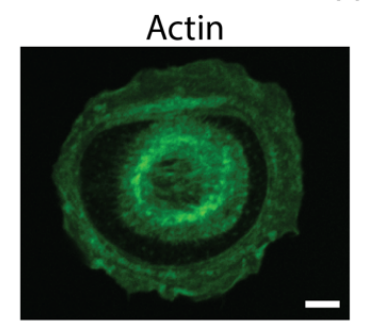

Primary Mouse Hepatocyte

C
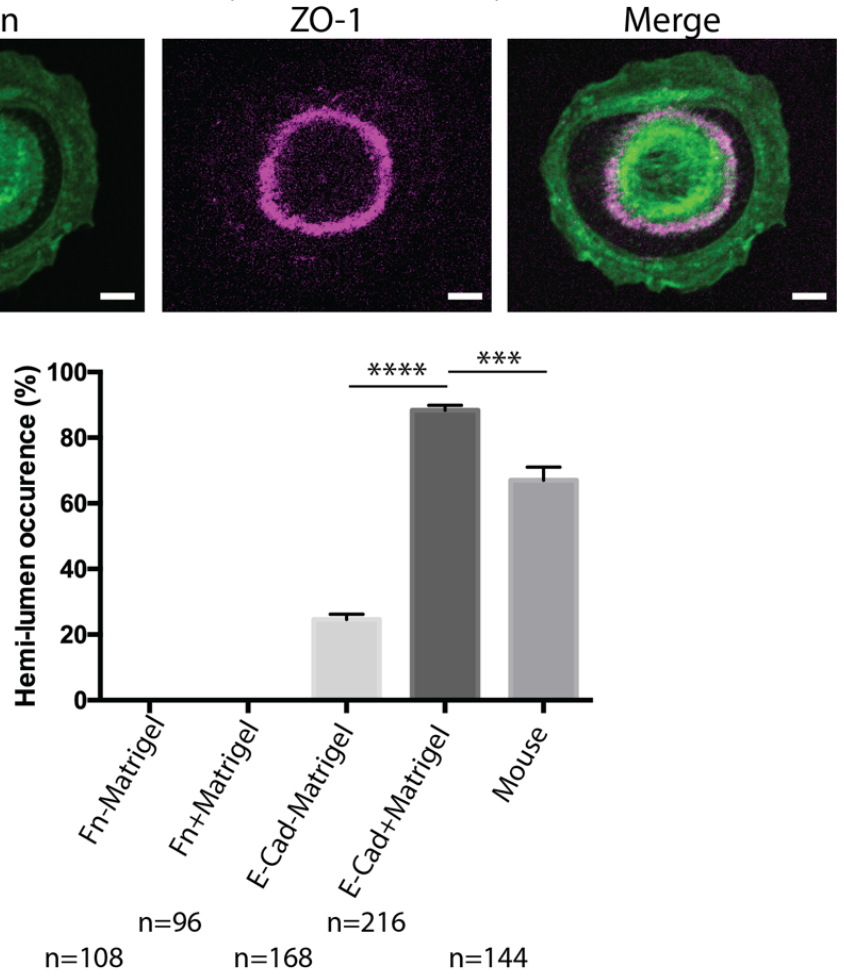

Supplementary Figure 2:

773 Combination of Cadherin and ECM signalling are necessary to form hemi-lumen in

774 large proportion of hepatocytes. a, Representative immunostaining images showing 775 the top and side view of single hepatocytes cultured in four distinct 776 microenvironments as indicated by the diagram. Scale bar, $5 \mu \mathrm{m}$. b, Representative 777 image showing that primary mouse hepatocyte are capable of forming similar actin 778 (Green) structure with ZO-1(purple) exclusively recruited to the contour as rat 779 hepatocyte when cultured on E-Cadherin coated island and and overlayed with 6\% 780 matrigel. Scale bar, $5 \mu \mathrm{m}$. c, Fraction of cells displaying central actin structure and 781 polarity phenotype in conditions described in a, b. The data of rat and mouse 782 hepatocyte is collected from 3 and 2 independent experiments respectively. ***, p 783 value $<0.001, * * * *$, p value $<0.0001$ 
bioRxiv preprint doi: https://doi.org/10.1101/636654; this version posted May 15,2019 . The copyright holder for this preprint (which was

not certified by peer review) is the author/funder, who has granted bioRxiv a license to display the preprint in perpetuity. It is made available under aCC-BY-NC-ND 4.0 International license.

a

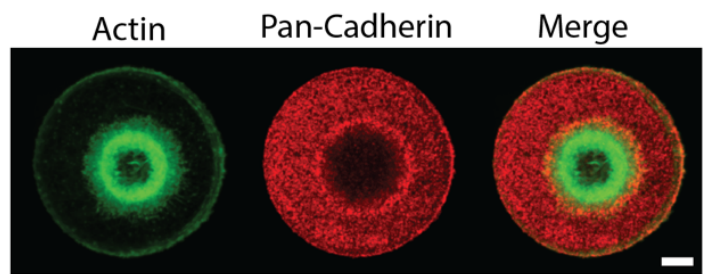

Alpha-Tubulin

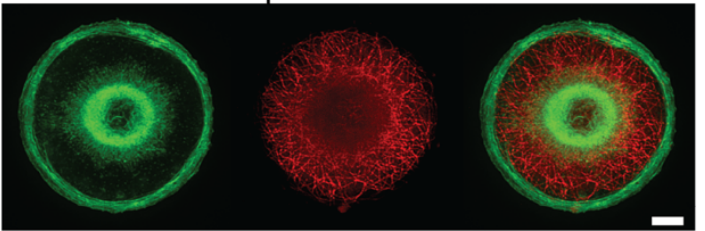

Myosin IIA

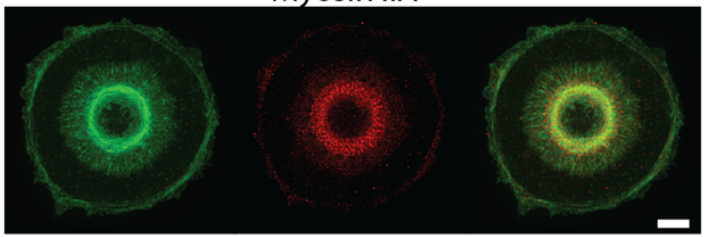

ZO-2

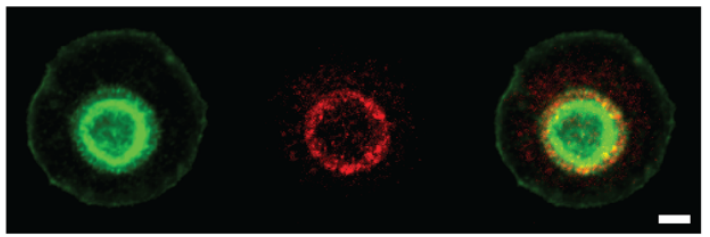

Claudin-3

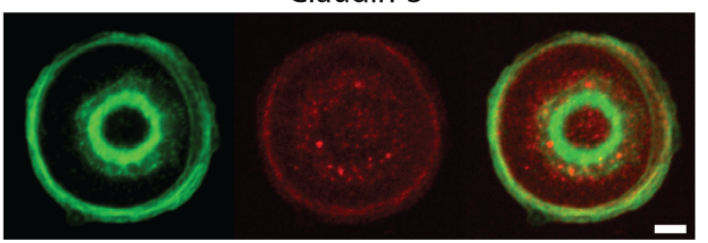

b
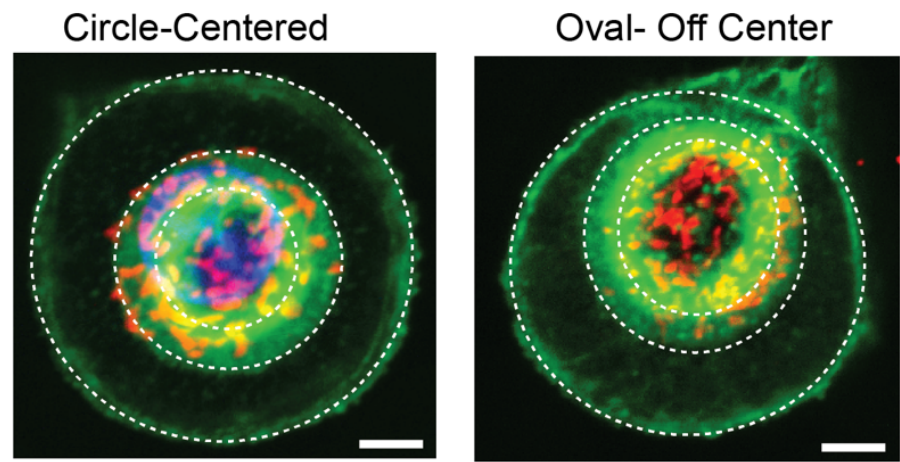

DAPI | Actin | Grasp 65

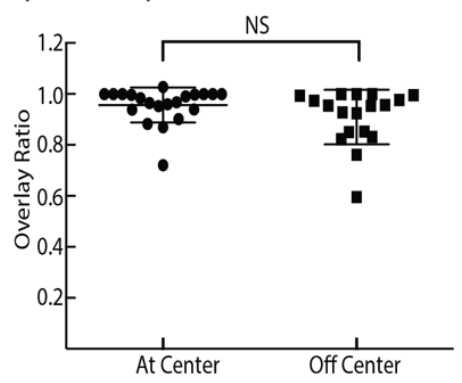

Mrp2 Merge

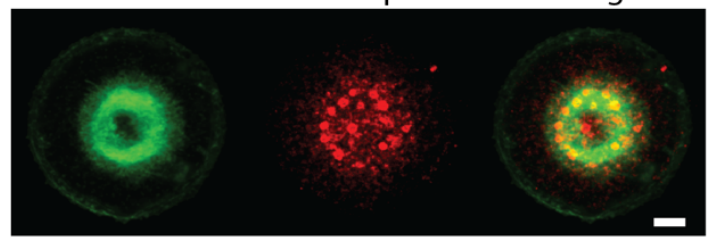

Par-3

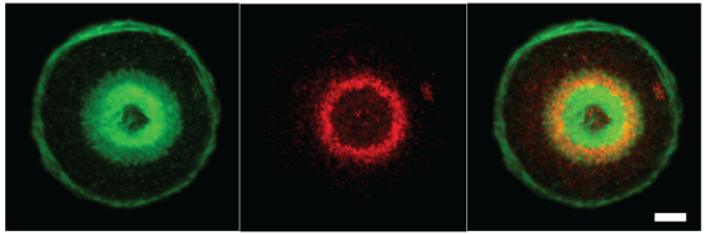

ZO-1

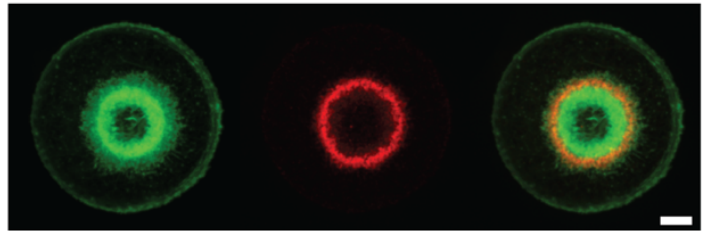

Claudin -1

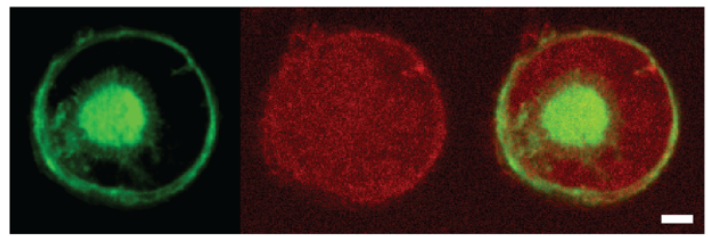

Occludin

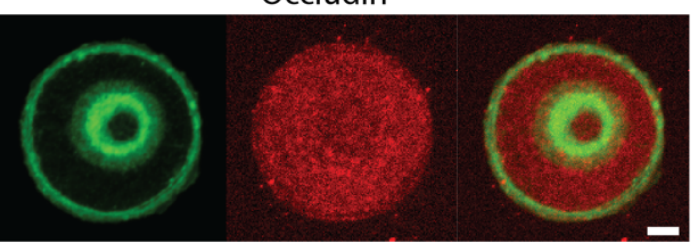

$3 \mathrm{D}$ reconstruction 
bioRxiv preprint doi: https://doi.org/10.1101/636654; this version posted May 15,2019 . The copyright holder for this preprint (which was

not certified by peer review) is the author/funder, who has granted bioRxiv a license to display the preprint in perpetuity. It is made available under aCC-BY-NC-ND 4.0 International license.

787 Supplementary Figure 3:

788 The distribution of polarity markers protein and organelles in hemi-lumen. a, Split 789 color images for Fig. 2b. Representative immunofluorescence images of ZO-2, 790 Claudin-1, Occludin and Alpha-Tubulin that are not presented on Fig 2b. Scale bar, $7915 \mu \mathrm{m} . \mathbf{b}$, Representative images showing relative location of actin structure (green) 792 and maximum Z projection of Golgi staining (by Grasp65 in red) in the cases when 793 the hemi-lumens at the centre or side of cell/substrate interface. 3D reconstruction 794 (middle) of image stack for left panel showing the Golgi(red) is situated right above 795 lumen area (Cyan). Plots (right) showing the projection of Golgi structure highly 796 overlapped with lumen area. We do not observe any significant difference between 797 both cases of lumen location. $n=21$ for centered lumen at centre, $n=19$ for off798 centered lumen. 
803

804

805

806

807

808

809

810

811

812

813

814

815

816

817

818

819

820

821

822 a
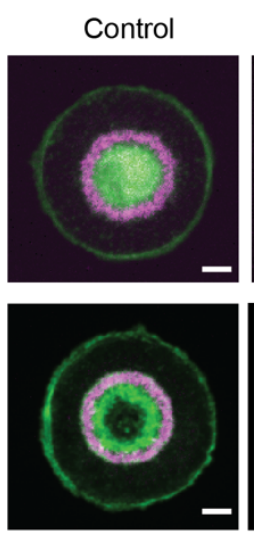
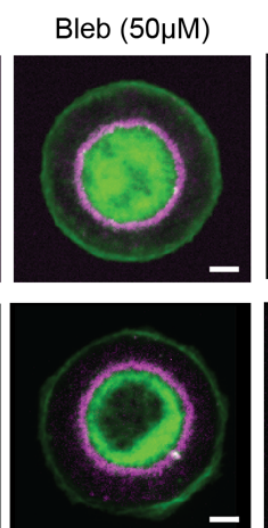

Keto $(10 \mu \mathrm{M})$
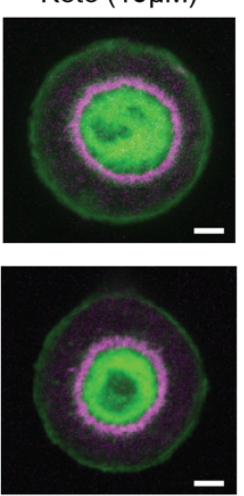

b

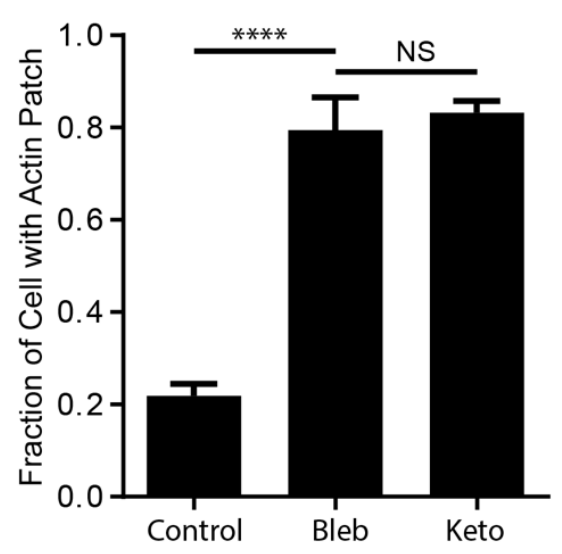

\section{Supplementary Figure 4:}

Inhibition of actomyosin contractility or of bile acid synthesis hinders the reorganization of the actin structures from dense patches to rings. $a$, Representative images of actin (green) and ZO-1 (purple) for both patch (top) and ring (bottom) morphologies in control, $50 \mu \mathrm{M}$ blebbistatin (Blebb) and $10 \mu \mathrm{M}$ ketoconazole (Keto) treated hepatocytes. Scale bar: $5 \mu \mathrm{m} \mathrm{b}$, Fraction of cells with dense patch actin structures at steady state is significantly increased after blebbistatin or ketoconazole treatments. Bar chart shows the mean \pm SD from 3 independent experiments $(n=146, n=129$, and $n=108$ cells in control, Bleb (Blebbistatin) and Keto (Ketoconasol) group respectively). ${ }^{* * *}, \mathrm{p}<0.0001, \mathrm{NS}$, not significant. Two-sided unpaired t-test was performed to calculate $p$ value. 
bioRxiv preprint doi: https://doi.org/10.1101/636654; this version posted May 15,2019 . The copyright holder for this preprint (which was not certified by peer review) is the author/funder, who has granted bioRxiv a license to display the preprint in perpetuity. It is made available under aCC-BY-NC-ND 4.0 International license.

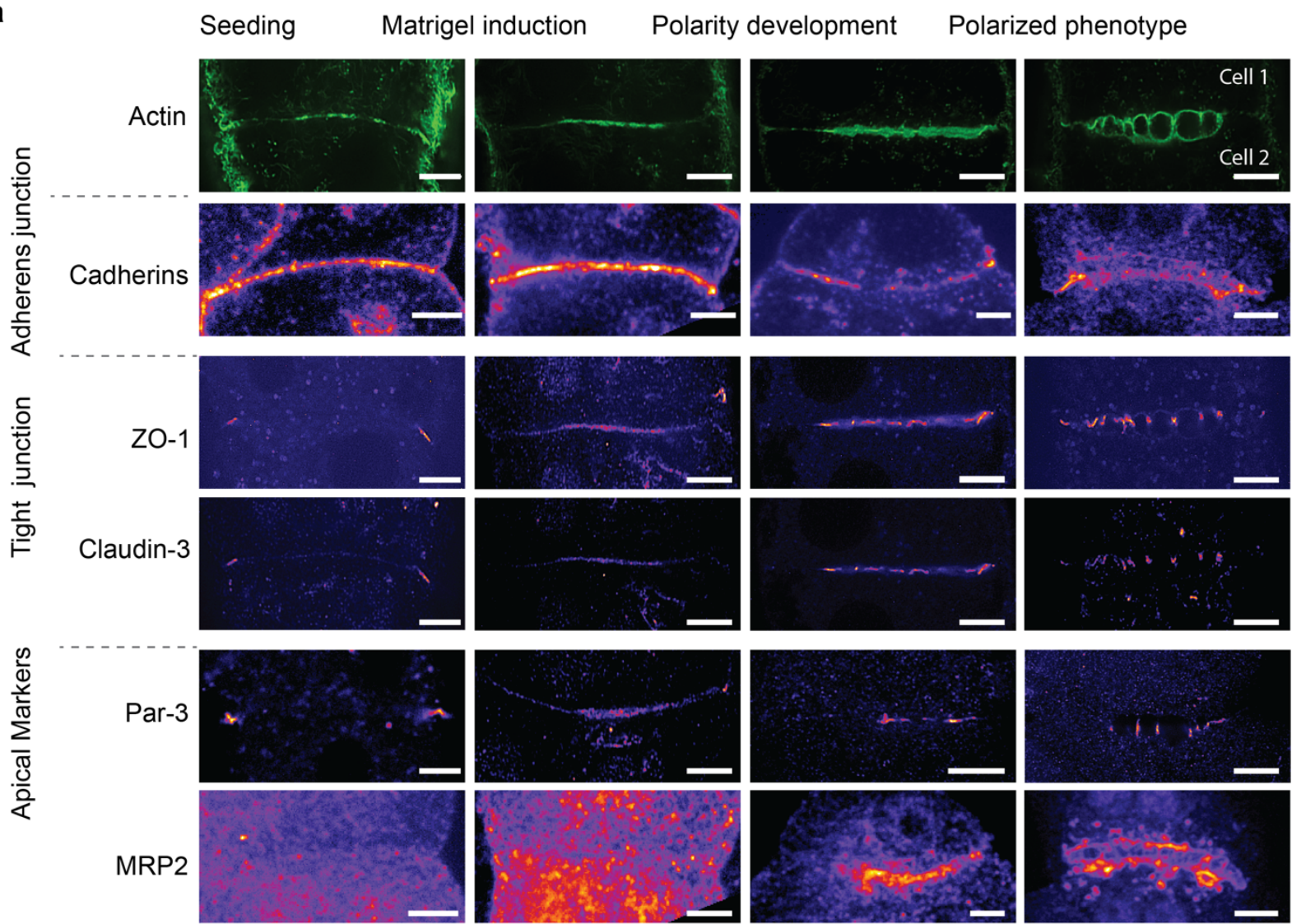

\section{Supplementary Figure 5:}

825 Evolution of the distribution of polarity markers around the cell-cell interface 826 during in vivo polarisation.

827 Representative structure illumination microscopy (SIM) images of actin and hepatic

828 polarity related proteins for bile canaliculi formed a lumen between two primary 829 hepatocytes at different stages of polarity development. Actin, cadherin and ZO1 830 and Claudin 3 images are obtained from quadruple immunostaining of the cells. Par 8313 and MRP2 images are obtained from cells with similar actin morphologies. 
a
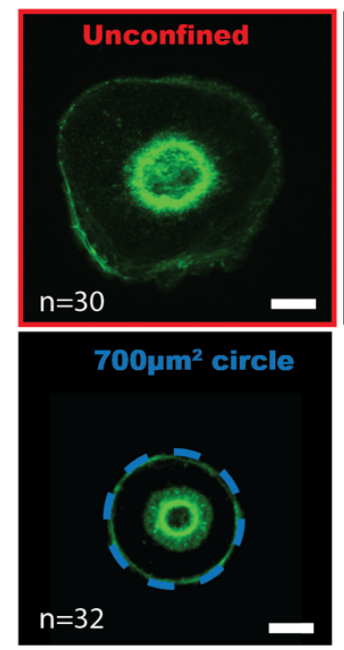

b

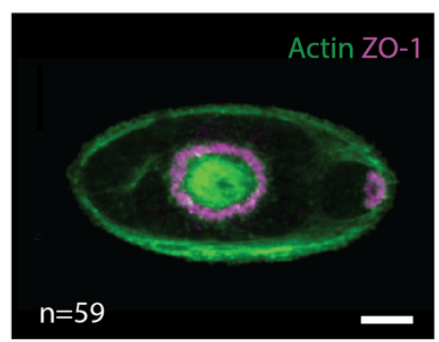

NS

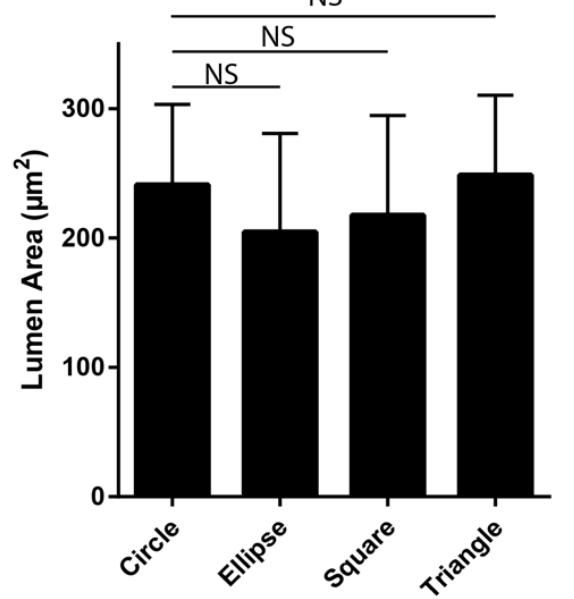

On same pattern area: $1200 \mu \mathrm{m}^{2}$
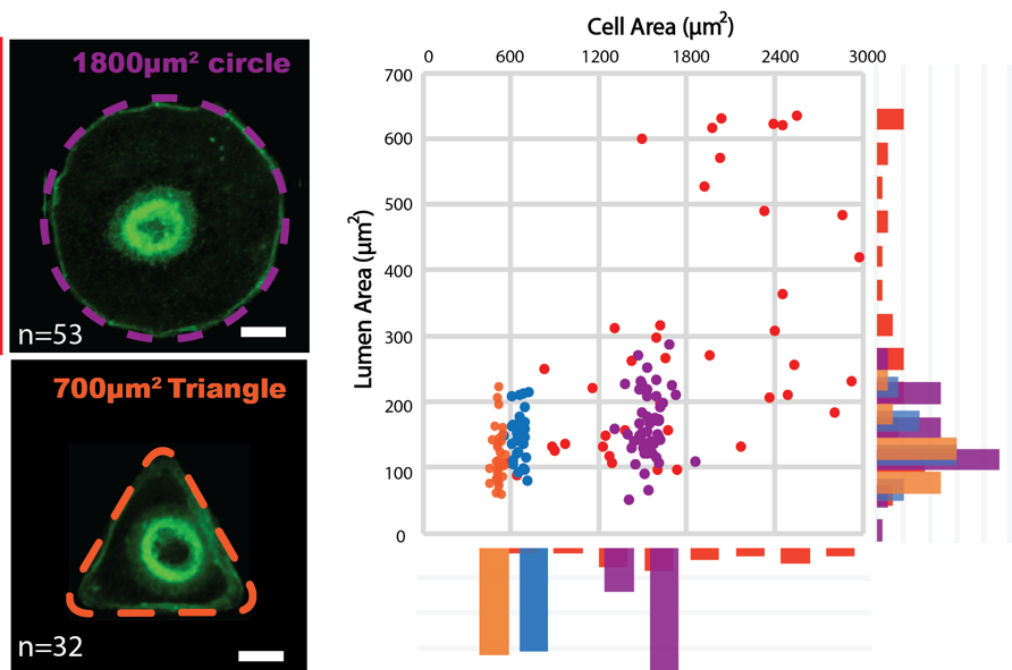
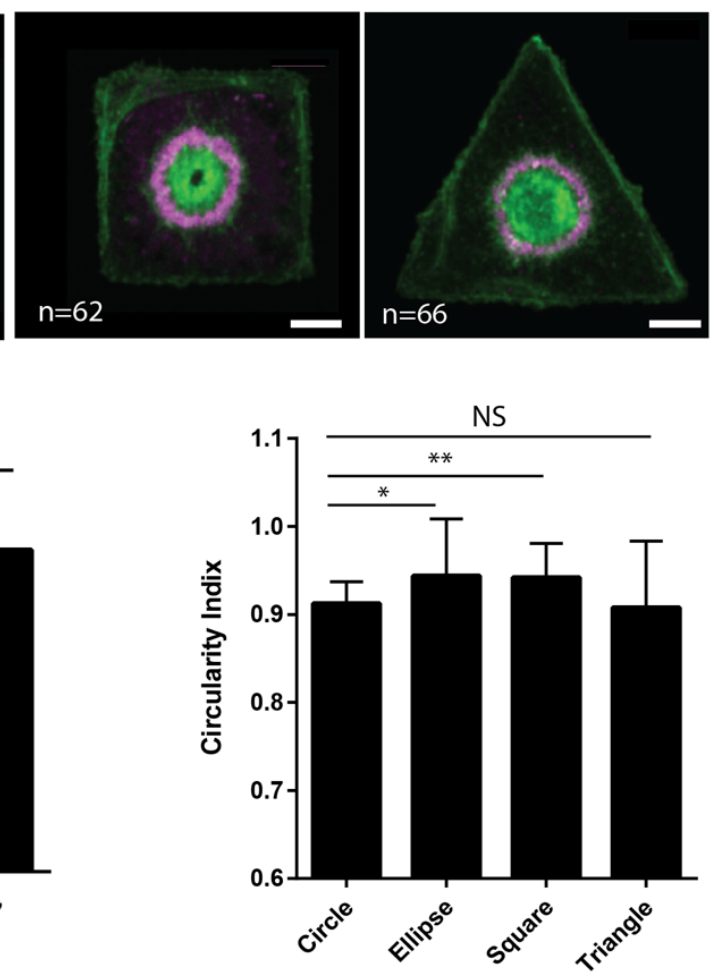

\section{Supplementary Figure 6:}

The hemi-lumen size and shape are relatively independent of the cell spreading area and geometry. a, Left panel: representative images of actin (green) showing the sizes and shapes of hemi-lumens formed by hepatocytes spreading on ECadherin coated surface with different areas. The patterns are outlined by coloured dashed lines. Scale bar: $5 \mu \mathrm{m}$. Right panel: Distribution of lumens area vs and cell area. Data from cells on different spreading areas or geometries are color-coded corresponding to the color of the pattern outlines depicted on the left panel. The data are pooled from 3 independent experiments. b, Top: typical central actin and ZO-1 staining of hepatocyte seeding on elliptic, square and triangular pattern with area of $1200 \mu \mathrm{m}^{2}$. bottom: bar charts showing the lumen area (left) and circularity 
bioRxiv preprint doi: https://doi.org/10.1101/636654; this version posted May 15,2019 . The copyright holder for this preprint (which was

not certified by peer review) is the author/funder, who has granted bioRxiv a license to display the preprint in perpetuity. It is made available under aCC-BY-NC-ND 4.0 International license.

index (right) of hemi-lumen in cells confined on different cell geometry. NS, not

848 significant, $* *, p<0,01, *, p<0,05$.

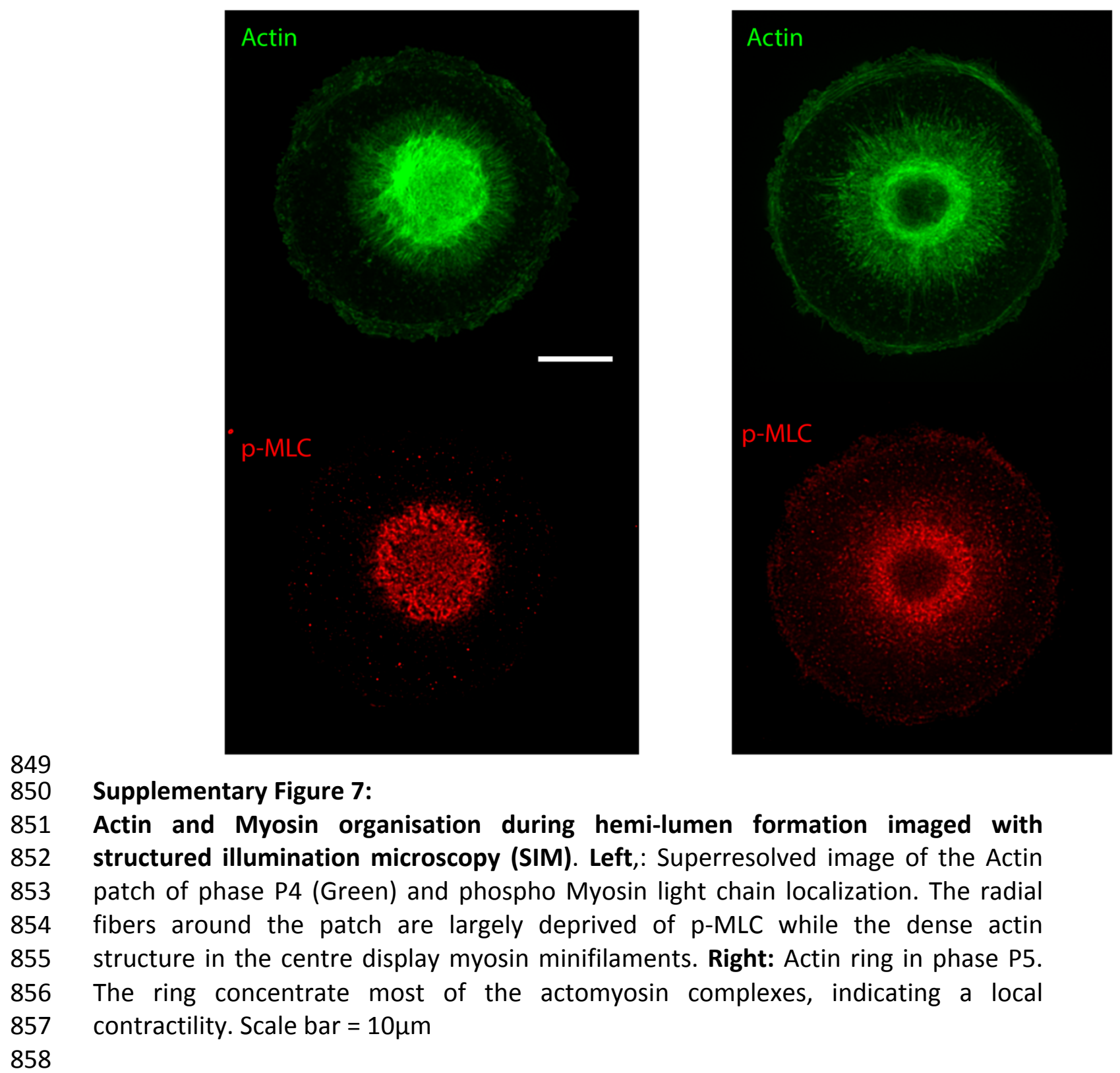




\section{Caption Supplementary movies:}

Supplementary Movie 1: live RICM imaging of the hemi-lumen in control conditions. Note the central ring that moves radially indicating a dome shape structure of about $863200 \mathrm{~nm}$ height on top of the coverslip.

Supplementary Movie 2: live RICM imaging of the hemi-lumen under Ketokonazole $10 \mathrm{uM}$. The inhibition of bile secretion leads to a large reduction of vertical fluctuation (amplitude and frequency). The fluctuations are no longer radial (lumen pulsating) but rather diffused and lateral, indicating a mere membrane fluctuation.

Supplementary Movie 3: live RICM imaging of the hemi-lumen in UDCA (40uM) 871 treated cells. This treatment stimulates bile salt secretion. Multiple interference 872 rings in the center of the lumen indicates a much-inflated geometry compared to 873 control case.

Supplementary Movie 4: live RICM imaging of the hemi-lumen on doughnut patterns in control conditions. The central fluctuations are fully random compared to disc patterns. It indicates the absence of coordinated pulsations that are replaced by simple fluctuations of the free membrane. 